\title{
acerca del hormigón de la Base de Rota
}

\author{
ALVARO LOPEZ RUIZ \\ Doctor en Química Industrial \\ Jefe de Laboratorios de Cimentaciones Especiales, S. A.
Procedimientos Rodio
}

\begin{abstract}
Con reconocimiento a las entidades Thompson \& Lichtner Co. Inc, BrownRaymond-Walsh y O. I. C. C., supervisores del Laboratorio de ensayo y proyecto de materiales de construcción de la Base de Rota, en el cual el autor trabajó como "Senior testing engineer", por las facilidades dadas para la realización de este trabajo.
\end{abstract}

\section{Introducción}

Siempre es útil, y tal vez más en la actual coyuntura, el poder comparar las propiedades y métodos de obtención de los productos industriales, con los de los análogos extranjeros, a fin de conseguir una ponderación realista de los mismos. Esto ha inducido al autor, que ha trabajado durante cinco años en el Laboratorio de ensayo y proyecto de materiales de construcción de la Base aeronaval de Rota, a publicar el presente trabajo, en el que se detallan los diversos tipos de hormigones y cementos utilizados en la construcción de la Base.

El Laboratorio estuvo dirigido, primeramente, por la compañía norteamericana Thompson \& Lichtner Co., Inc., y después por el contratista principal Brown-Raymond-Walsh, con la supervisión del O. I. C. C.

Era misión del laboratorio, además de la normal de control, proporcionar todo el asesoramiento y ayuda técnica necesarios a los constructores.

La presente publicación se ha dividido en las dos partes siguientes:

a Dosificaciones, resistencias y características medias de los hormigones de cemento portland utilizados en la construcción de la Base aeronaval de Rota.

b Características fisicoquímicas y comportamiento en hormigón de algunos cementos de muy diversas procedencias.

\section{Dosificaciones, resistencias y características medias de los hor- migones de cemento portland utilizados en la construcción de la Base aeronaval de Rota}

En esta primera parte del trabajo se dan las dosificaciones, las resistencias, y otras características de los hormigones utilizados en la construcción de la Base de Rota durante el período 1955-1960, por el contratista principal Brown-Raymond-Walsh. Todo el hormigón, unos $500.000 \mathrm{~m}^{3}$, ha sido fabricado bajo la inspección y control del Laboratorio de ensayo de materiales de construcción. Ha sido misión del laboratorio proyectar y ensayar periódicamente los distintos tipos de hormigón y sus constituyen- 
tes, así como cuidar de su correcta puesta en obra, colaborando en esta misión con los inspectores a pie de obra. Los ensayos, mientras no se indique lo contrario, se han realizado siguiendo las normas A. S. T. M.

Se han utilizado cementos portland procedentes de Alemania, Bélgica, Dinamarca, Francia, Portugal, Israel, Yugoslavia, etc, los euales debían de cumplir con las normas «The British B. S. 12-1947\%, más la condición de tener una expansión en el ensayo de autoclave no mayor del 0,5 por 100 , o con las «Federal Specification SS-C-192a Type I».

El clima de Rota, a excepción de los días que sopla el viento cálido del tevante, es templado y húmedo. No hay peligro de heladas.

Se ha dividido la exposición en Ios apartados siguientes:

1. Aridos empleados en la fabricación de los hormigones.

2. Hormigones para estructuras corrientes.

3. Hormigones para el pavimento del aeropuerto.

4. Determinación del tamaño máximo óptimo de árido para la fabricación del hormigón de pavimento del aeropuerto.

5. Hormigones para el puerto.

6. Hormigones para viguetas pretensadas.

7. Hormigones para los elementos prefabricados de las viviendas familiares.

\section{Aridos empleados en la fabricación de los hormigones}

Aun cuando esporádicamente se ha utilizado grava de otras procedencias, la mayor parte del árido grueso empleado ha sido grava caliza de machaqueo, procedente de la cantera del Berrueco, cerca de Chiclana (Cádiz). Este material ha dado un resultado excelente, y se ha aprovechado íntegramente. La arena producida durante la fabricación de la grava se ha utilizado como «finos» para hormigón asfáltico, o mezclada con arena de playa para árido fino de hormigén de cemento portland, ete.

Los áridos fueron fabricados, en su mayor parte, por la empresa española Cubiertas y Tejados, Sociedad Anónima.

Las «plantas» de fabricación del árido grueso estaban constituidas por la machacadora propiamente dicha y el equipo mecánico para la separación por tamaños de la grava. Cada clase de grava, designada por su tamaño máximo nominal, debía tener una granulometría determinada.

El árido fino se ha obtenido de dos maneras:

a) Mezclando, en una instalación al efecto, dos tipos de arena de playa, una gruesa y otra fina, para conseguir una granulometría dentro de las especificaciones.

b) Mezclando sobre el terreno, con traílla o elevadora Barber-Green, arena de playa y arena de machaqueo, dispuestas previamente en capas de espesor dado.

Las características medias de los áridos grueso y fino utilizados en la fabricación del hormigón, se dan en las tablas números 1 y 2 .

La arena de playa se utilizó exclusivamente como árido fino desde el comienzo de las obras, en el verano de 1955 hasta marzo de 1958; posteriormente se utilizó arena de playa mezclada con arena de machaqueo. 
TABLA 1.-Granulometría y características medias del áxido grueso. (Los limites de las especificaciones van entre paréntesis.)

\begin{tabular}{|c|c|c|c|c|c|c|c|c|c|c|c|c|}
\hline $\begin{array}{l}\text { Tamaño } \\
\text { máxímo } \\
\text { (pulgadas) }\end{array}$ & $6 \% 1$ & f & 3 & $\begin{array}{c}\text { Luces de lo } \\
2^{1 / 2}\end{array}$ & $\begin{array}{c}\text { s tamices } \\
2\end{array}$ & $\begin{array}{c}\text { de unalla } \\
1^{1 / 1}\end{array}$ & $\begin{array}{c}\text { 1adradn, } \\
1\end{array}$ & $\begin{array}{c}\text { pulgadas } \\
3 / 4\end{array}$ & $2 / s$ & $N^{2} 4$ & $\mathrm{~N} \cdot 8$ & $\begin{array}{l}\text { Módulo } \\
\text { de } \\
\text { finura }\end{array}$ \\
\hline- & $(100)$ & $(90-100)$ & $(35-60)$ & - & $(0-5)$ & - & - & - & - & - & - & - \\
\hline 6 & 100 & 92 & 42 & 8 & 2 & - & - & - & - & - & - & 9,65 \\
\hline - & - & - & $(100)$ & $(90-100)$ & $(35-70)$ & $(0-15)$ & - & $(0-5)$ & - & - & - & - \\
\hline $21 / 2$ & - & - & 100 & 97 & 61 & 14 & - & 4 & - & - & - & 8,80 \\
\hline- & - & 一 & - & - & $(100)$ & $(90-100)$ & $(20-55)$ & $(0-15)$ & $(0-5)$ & - & - & - \\
\hline $11 / 2$ & - & - & - & - & 100 & 95 & 46 & 14 & 3 & - & - & 7,85 \\
\hline- & - & - & - & - & - & - & $(100)$ & $(90-100)$ & $(20-55)$ & $(0-10\rangle$ & $(0-5\rangle$ & - \\
\hline $3 / 4$ & - & - . & 一 & - & - & - & 100 & 94 & 84 & 5 & 3 & 6,60 \\
\hline
\end{tabular}

Las especificaciones aplicadas al árido grueso y fino fueron las a Federal Specifications SS-A-28Ib*, excepto donde se indicó otra cosa.

Peso específico del árido grueso (saturado superficie seca) : 2,67.

Absorción : 0,8 por 100 .

Abrasión, Los Angeles: 30 por 100. Máxima permitida: 40 por 100 .

Materia orgánica : Exento.

TABLA 2-Granulometría y características medias del árido fino.

\begin{tabular}{|c|c|c|c|}
\hline Tamiz A. S. T. M. & $\begin{array}{l}\text { Arena de playa } \\
\text { (o/n que pasa) }\end{array}$ & $\begin{array}{c}\text { Arema de playa } \\
\text { y arena de machaqueo } \\
(\% \text { que pasa) }\end{array}$ & $\begin{array}{l}\text { Especifleaeiones } \\
\text { (\% que pasa) }\end{array}$ \\
\hline 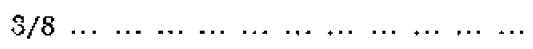 & 100 & 100 & 100 \\
\hline $\begin{array}{llllllllll}\text { Número } & 4 & \ldots & \ldots & \ldots & \ldots & \ldots & \ldots & \ldots & \ldots\end{array}$ & 96 & 97 & $95-100$ \\
\hline $\begin{array}{lllllllllll}\text { Número } & 8 & \ldots & \ldots & \ldots & \ldots & \ldots & \ldots & \ldots & \ldots\end{array}$ & 89 & 82 & $70-90$ \\
\hline $\begin{array}{llllllllll}\text { Número } & 16 & \ldots & \ldots & \ldots & \ldots & \ldots & \ldots & \ldots & \ldots\end{array}$ & 79 & 70 & $45-75$ \\
\hline Número $\begin{array}{ccccccccc} & 30 & \ldots & \ldots & \ldots & \ldots & \ldots & \ldots & \ldots\end{array}$ & 62 & 53 & $25-55$ \\
\hline $\begin{array}{lllllllllll}\text { Número } & 50 & \ldots & \ldots & \ldots & \ldots & \ldots & \ldots & \ldots & \ldots\end{array}$ & 25 & 28 & $10-30$ \\
\hline $\begin{array}{lllllllll}\text { Número } & 100 & \ldots & \ldots & \ldots & \ldots & \ldots & \ldots & \ldots\end{array}$ & 2,5 & 9 & $2-10$ \\
\hline Módulo de finura $\ldots \ldots \ldots \ldots \ldots \ldots$ & 2,45 & 2,60 & Mínimo: 2,3; Máximo: 3,1 \\
\hline Peso especifico (saturado superficie seca). & 2,58 & 2,61 & \\
\hline $\begin{array}{llllllllll}\text { Absorción } & \ldots & \ldots & \ldots & \ldots & \ldots & \ldots & \ldots & \ldots & \ldots\end{array}$ & $0,8 \%$ & $0,9 \%$ & \\
\hline Materia orgánica $\ldots \ldots \ldots \ldots$ & Exento & Exento & \\
\hline
\end{tabular}

En la fabricación de hormigones de tamaño máximo de árido superior a $3 / 4$ de pulgada fue preciso utilizar dos o más clases de grava para poder conseguir una granulometría combinada dentro de los límites de las espectficaciones.

En la tabla número 3 se dan, entre paréntesis, los límites de las especificaciones, las granulometrías medias combinadas de la grava en función del tamaño máximo, y las proporciones utilizadas de cada clase de grava. 
TABLA 3.-Granulometrías comblnadas medlas y proporcjones a mezclar de cada clase de grava, en función del tamaño máximo. (Los limites de las especificaciones van entre paréntesis.)

\begin{tabular}{|c|c|c|c|c|c|c|c|c|c|c|c|c|}
\hline $\begin{array}{c}\text { Tamaño } \\
\text { mixrimo } \\
\text { (pulgadas) }\end{array}$ & $6^{1 / 2}$ & 6 & 3 & $\mathbf{2}^{1 / 2}$ & 2 & $11 / \%$ & 1 & $3 / 4$ & $3 / 9$ & N.0 4 & $\begin{array}{l}\text { Mödulo } \\
\text { de } \\
\text { finura } \\
\text { medla }\end{array}$ & $\begin{array}{l}\text { Proporoionts } \\
\text { a mexclar de eada } \\
\text { clare de grava }\end{array}$ \\
\hline$-\frac{}{6}$ & $\begin{array}{l}(100) \\
100\end{array}$ & $\begin{array}{c}(90-100) \\
96\end{array}$ & $\begin{array}{c}(55-85) \\
71\end{array}$ & - & - & $\begin{array}{c}(30-55) \\
41\end{array}$ & - & $\begin{array}{c}(15-85) \\
20\end{array}$ & $\begin{array}{c}(5-20) \\
8\end{array}$ & $\begin{array}{c}(0-5) \\
2\end{array}$ & $\overline{8,60}$ & $\begin{array}{l}50 \%(6)+10 \%(21 / 2)+ \\
+25 \%(11 / 2)+15 \%(3 / 4\end{array}$ \\
\hline $2 \overline{1 / 2}$ & - & - & $\begin{array}{c}(100) \\
100\end{array}$ & $\begin{array}{c}(90-100) \\
98\end{array}$ & - & $\begin{array}{c}(35-60) \\
55\end{array}$ & - & $\begin{array}{c}(10-40) \\
29\end{array}$ & $\begin{array}{c}(0-15) \\
10\end{array}$ & $\begin{array}{r}(0-5) \\
2\end{array}$ & $\overline{8,05}$ & $\begin{array}{l}50 \%(21 / 2)+25 \% \\
(11 / 2)+25 \%(3 / 4)\end{array}$ \\
\hline $1 \overline{1 / 2}$ & - & - & - & - & $\begin{array}{l}(100) \\
100\end{array}$ & $\begin{array}{c}(95-100) \\
97\end{array}$ & - & $\begin{array}{c}(35-60) \\
54\end{array}$ & $\begin{array}{c}(10-30) \\
20\end{array}$ & $\begin{array}{r}(0-5) \\
3\end{array}$ & $\overline{7,25}$ & $50 \%(1 / 2)+50 \%(3 / 4)$ \\
\hline$\overline{3 / 4}$ & - & 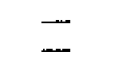 & - & - & - & - & $\begin{array}{c}(100) \\
100\end{array}$ & $\begin{array}{c}(90-100) \\
94\end{array}$ & $\begin{array}{c}(20-55) \\
34\end{array}$ & $\frac{(0-10)}{5}$ & $\overline{6,60}$ & $100 \%(\%)$ \\
\hline
\end{tabular}

A excepción de la grava de $21 / 2$ pulgadas, las curvas granulométricas de las otras tres clases de grava responden bastante bien a la ecuación:

$P=100 \frac{\sqrt{d}-0,433}{\sqrt{D}-0,433}$, en donde $P$ es el tanto por ciento acumulado que pasa por el tamiz de abertura $d$ y $D$ es el tamaño máximo nominal de la grava.

Esta fórmula se obtiene fácilmente de la de Fuller, $P=\sqrt{d / D}$, que representa al árido total, es decir, grava más arena.

\section{Hormigones para estructuras corrientes}

\section{a) Generalidades.}

Los hormigones que se describen seguidamente son los utilizados en la construcción de las edificaciones y obras corrientes de la Base.

El volumen de hormigón de este grupo puede estimarse en cerca de $150.000 \mathrm{~m}^{3}$. La mayor parte de este hormigón se dosificó por pesada en una «planta» dosificadora («noble movile batching plant») que, mediante cinta transportadora, vertía el cemento y los áridos, ya pesados, en camiones hormigoneras que amasaban el hormigón a la vez que lo transportaban a la obra. El agua se dosificó por volumen.

Las especificaciones del hormigón se dan en el apéndice I, habiérdose añadido algunas observaciones pertinentes entre paréntesis.

\section{b) Caracteristicas fisicoquímicas medias de los cementos portland empleados en los hormigones.}

En la tabla núm. 4 se dan las características fisicoquímicas medias de los cementos portland utilizados en la fabricación de los hormigones para estructuras corrientes.

TABLA 4.-Características fisicoquímicas medias de los cementos portland empleados en los hormigones para estructuras corrientes.

$\underset{12-1947}{\text { Normas }} \mathbf{S}$

Máx. 1,0
-
Máx. 4,0
Máx. 2,75
Máx. 3,0
Mín. 0,66
Máx. 1,02

Sílice $\ldots \ldots \ldots \ldots \ldots \ldots \ldots \ldots \ldots$ Residuo insoluble $\ldots \ldots \ldots \ldots \ldots$

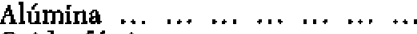
Oxido férrico $\ldots \ldots \ldots \ldots \ldots$

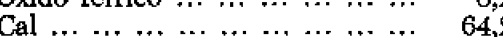
Magnesia ....................... Anhídrido sulfúrico ... $\ldots \ldots \ldots \ldots$ Pérdida al fuego ... ....... ... ...

Máx 1,09
Indice de saturación en cal ... ... 0,92
Normas B. $\mathbf{s}$. 12-1847

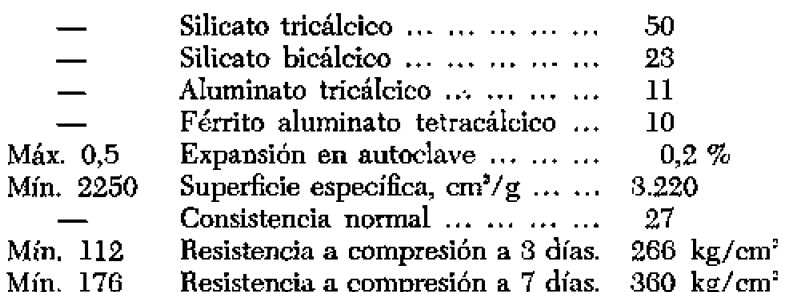




\section{c) Dosiffcaciones y resistencias medias de los hormigones.}

Las dosificaciones medias de los hormigones del grupo, en los que se ha utilizado como árido fino arena de playa mezclada con arena de machaqueo, se dan en la tabla núm. 5. Estas dosificaciones medias se ajustaron frecuentemente a lo largo de la obra, de acuerdo con las variaciones de los áridos o del ambiente. Así, por ejemplo, en verano el hormigón precisó algo más de agua que en invierno para conseguir la misma consistencia.

Cuando variaba el módulo de finura se ajustó la relación arena/árido total, de forma que se mantuviera constante el módulo de finura de la granulometría combinada del árido total.

TABLA 5.-Dosificaciones medias de los hormigones para estructuras corrientes.

\begin{tabular}{|c|c|c|c|c|c|c|c|c|}
\hline $\begin{array}{l}\text { Resistencia } \\
\text { nominal } \\
\text { a } 28 \text { días } \\
\left(\mathrm{kg} / \mathrm{cm}^{2}\right)\end{array}$ & $\begin{array}{l}\text { Tamaño } \\
\text { maximo } \\
\text { del frido } \\
\text { (pulgadas. }\end{array}$ & $\begin{array}{c}\text { Máximo } \\
\text { astento } \\
\text { (pulgadas) }\end{array}$ & $\begin{array}{l}\text { Relación } \\
\text { agua/cemento }\end{array}$ & $\begin{array}{l}\text { Cemento } \\
\left(\mathrm{kg} / \mathrm{m}^{3}\right)\end{array}$ & $\underset{\left(\mathrm{kg} / \mathrm{m}^{3}\right)}{\mathrm{Agua}}$ & $\underset{\left(\mathrm{kg} / \mathrm{m}^{2}\right)}{\operatorname{Areng}}$ & $\underset{\left(\mathrm{kg} / \mathrm{m}^{3}\right)}{\operatorname{GraYa}}$ & $\begin{array}{c}\text { Relacion } \\
\text { arent/arido } \\
\text { total } \\
\text { (volumen) }\end{array}$ \\
\hline 140 & $3 / 4$ & 4 & 0,75 & 254 & 191 & 955 & 955 & 0,505 \\
\hline 176 & $3 / 4$ & 4 & 0,69 & 279 & 193 & 930 & 955 & 0,500 \\
\hline 176 & $3 / 4$ & 6 & 0,69 & 296 & 204 & 900 & 980 & 0,495 \\
\hline 211 & $3 / 4$ & 4 & 0,62 & 316 & 196 & 895 & 950 & 0,490 \\
\hline 211 & $3 / 4$ & 6 & 0,62 & 335 & 207 & 865 & 930 & 0,49 \\
\hline 246 & $3 / 4$ & 4 & 0,55 & 361 & 199 & 855 & 945 & 0,48 \\
\hline 140 & $11 / 2$ & 3 & 0,75 & 230 & 173 & 815 & 1.175 & 0,415 \\
\hline 176 & $11 / 2$ & 3 & 0,69 & 254 & 175 & 790 & 1.175 & 0,408 \\
\hline 176 & $11 / 2$ & 4 & 0,60 & 261 & 180 & 775 & 1.165 & 0,405 \\
\hline 211 & $11 / 2$ & 3 & 0,62 & 286 & 177 & 765 & 1.165 & 0,40 \\
\hline 211 & $11 / 2$ & 4 & 0,62 & 294 & 182 & 755 & 1.150 & 0,40 \\
\hline 246 & $11 / 2$ & 3 & 0,55 & 327 & 180 & 725 & 1.165 & 0,39 \\
\hline
\end{tabular}

Los hormigones de la tabla núm. 5, de resistencia nominal menor de $176 \mathrm{~kg} / \mathrm{cm}^{2}$, se utilizaron en obras de tipo secundario, nunca en elementos estructurales.

Las resistencias medias de los hormigones de la tabla núm. 5, determinadás en probetas cilíndricas de $6 \times 12$ pulgadas, tomadas en obra y curadas en cámara, se dan en la tabla núm. 6 .

TABLA 6.-Resistencias medias a compresión de los hormigones para estructuras corrientes. (Probetas tomadas en obra y curadas en cámara húmeda a $20^{\circ} \mathrm{C}$ ).

$\underset{\text { Relaciōn }}{\text { agua/cemento }}$

0,55
0,62
0,69
0,75

Resistencia
a y dias
(kg/ $\left./ \mathrm{cm}^{3}\right)$

235
194
168
145

$$
\begin{aligned}
& \text { Resistencis } \\
& \text { a } 28 \text { dias } \\
& \text { (kg/cm }) \\
& \\
& 313 \\
& 260 \\
& 225 \\
& 193
\end{aligned}
$$

\section{d) Coeficientes de variación de los resultados de resistencia del hormigón.}

La dispersión de los resultados de resistencia a 28 dias, de las probetas de hormigón de campo,

\begin{tabular}{|c|c|c|}
\hline $\begin{array}{l}\text { Tamaño máximo } \\
\text { dé árido } \\
\text { (pulgadas) }\end{array}$ & $\begin{array}{l}\text { Coefteiente } \\
\text { de } \\
\text { variacion }\end{array}$ & $\begin{array}{l}\text { Número de grupos de tres probetas } \\
\text { utilizados en el câleulo del eoef- } \\
\text { ciente de variación }\end{array}$ \\
\hline $\begin{array}{l}3 / 4 \\
11 / 2\end{array}$ & $\begin{array}{l}6,3 \% \\
8,3 \%\end{array}$ & $\begin{array}{r}113 \\
61\end{array}$ \\
\hline
\end{tabular}
viene dada por los coeficientes de variación dados en la tabla núm. 7 .

TABLA 7,-.-Coeficientes de variación de los resultados de resistencia a compresión a 28 dias de las prohetas de hormigón.

Se observa que el coeficiente de variación aumenta con el tamaño máximo del árido, lo que es lógico, pues cuanto mayor es el tamaño de la grava, es más difícil conseguir hormigón uniforme. 
e) Relación entre las resistencias medias de los hormigones amasados en el laboratorio y en obra.

En la tabla núm. 8 se dan las resistencias medias de los hormigones de la tabla núm. 5 amasados en el laboratorio, y la relación entre las resistencias de los hormigones equivalentes amasados en el laboratorio y en obra.

TABLA 8.-Resistencias medias a compresión de los hormigones de la tabla 5 , preparados en el laboratorio.

\begin{tabular}{|c|c|c|c|}
\hline $\begin{array}{l}\text { Helación } \\
\text { agua/eemento }\end{array}$ & $\begin{array}{c}\text { Resistemcia } \\
\text { a } 7 \text { dias } \\
\left(\mathrm{kg} / \mathrm{cm}^{3}\right)\end{array}$ & $\begin{array}{c}\text { Resigtencia } \\
\text { a } 28 \text { días } \\
\left(\mathrm{kg} / \mathrm{cm}^{2}\right)\end{array}$ & $\begin{array}{l}\text { Relación de resistencias } \\
\text { del hormigon amasado } \\
\text { en el laboratorio } \\
\text { y en la obra }\end{array}$ \\
\hline $\begin{array}{l}0,55 \\
0,62 \\
0,69 \\
0,75\end{array}$ & $\begin{array}{l}265 \\
211 \\
183 \\
154\end{array}$ & $\begin{array}{l}352 \\
284 \\
240 \\
208\end{array}$ & $\begin{array}{l}1,12 \\
1,09 \\
1,07 \\
1,08\end{array}$ \\
\hline 0,75 & & & 1,09 \\
\hline
\end{tabular}

De los valores de la tabla se deduce que, por término medio, el hormigón amasado en el laboratorio dio $9 \%$ más de resistencia que el hormigón equivalente de la obra.

\section{f) Probabilidad de obtener resultados de resistencia inferiores a la nominal.}

En la tabla núm. 9 se da la probabilidad de obtener resultados de resistencia inferiores a la resistencia nominal.

Los cálculos se han realizado con los coeficientes de variación dados en la tabla núm. 7; las resis. tencias a compresión a 28 días, de la tabla núm. 6 , y los gráficos, del «American Concrete Institute. A. C. 1. 214-57\%,

TABLA 9.-Probabilidad de obtener resultados de resistencias a compresión

a 28 días inferiores a la resistencia nominal.

$\begin{array}{cc}\begin{array}{c}\text { Tamaño maximo } \\ \text { de la grava } \\ \text { (pulgadas) }\end{array} & \begin{array}{c}\text { Probabilidad de obtener } \\ \text { restitidos inferiores } \\ \text { a la resigtencia nominal }\end{array} \\ 3 / 4 & 1 / 300 \\ 11 / 2 & 1 / 200\end{array}$

\section{g) Condición determinante de la dosificación de hormigón.}

En la segunda condición de recepción del hormigón (véase apéndice I) se especificaba que las resistencias en ningún caso deberían ser inferiores a las nominales. Esta condición, tomada al pie de la letra, desde un punto de vista probabilístico no tiene sentido, por lo que, en un material como el hormigón, dicha condición tal vez pueda evaluarse como la probabilidad 1 en 100 de obtener resultados inferiores a la resistencia nominal.

Es criterio del «American Concrete Institute, A. C. I. 214-57» que una probabilidad 1 en 10 indica un control razonable del hormigón para estructuras, aunque esto no signifique aceptación de resultados consecutivos inferiores a la resistencia nominal.

Según esto, y dados los resultados obtenidos, podría haberse aumentado algo la relación agua/cemento del hormigón, para rebajar la resistencia media, pero entonces no se hubiera cumplido con la tercera condición de recepción, relativa a la máxima relación agua/cemento admitida. Por consiguiente, ésta ha sido la condición determinante de la dosificación del hormigón. 


\section{Hormigón para el povimento del aeropuerto}

\section{a) Generalidades.}

Seguidamente se dan las características medias de los hormigones utilizados en la construcción del pavimento del aeropuerto de la Base, es decir, de la pista de vuelo, accesos y zona de estacionamiento de aviones.

El volumen de hormigón correspondiente a este grupo puede estimarse en cerca de $150.000 \mathrm{~m}^{3}$. Fue colocado por la empresa española de construcción Huarte y Cía.

El hormigón fue dosificado por pesada en dos estaciones de dosificación, una para los áridos y otra para el cemento. Los materiales pesados caían sobre la caja de un camión dividida en tres compartimientos. Cada compartimiento transportaba los materiales para un metro cúbico de hormigón, que se volcaban en la «pala de carga» de la hormigonera. El agua y el agente aireante líquido «Aeroliths eran dosificados automáticamente por volumen. Las amasadas fueron de $1 \mathrm{~m}^{3}$ y el tiempo de amasado de 1 minuto.

Las condiciones de recepción de este tipo de hormigón se dan en el apéndice II.

EI volumen de aire ociuido se mantuvo siempre próximo al límite inferior permitido, entre 3,0 y $3,4 \%$, debido al clima templado de Rota, sin peligro de heladas.

El asiento medio del hormigón fresco fue de $4,5 \mathrm{~cm}$. Cuando el tamaño del árido grueso era superior a $5 \mathrm{~cm}$, antes de realizar el ensayo de asiento se cribaba el hormigón fresco por una criba de malla cuadrada de $5 \mathrm{~cm}$ de luz.

Todo el hormigón se colocó con ayuda de vibradores. La frecuencia mínima exigida a las unidades de vibración intema fue de 3.300 y a las montadas en el esparcidor de 3.500 vibraciones por minuto.

\section{b) Caracteristicas fisicoquímicas medias de los cementos utilizados.}

La mayor parte del cemento portland utilizado en el hormigón de pavimento pertenece a las dos divisiones siguientes:

a) Cementos alemanes,

b) Cemento yugoslavo «Deux Lions».

Las características fisicoquímicas medias de dichos cementos se dan en la tabla núm. 27, en las columnas correspondientes a « 4 cementos alemanes» y « 1 cemento yugoslavo».

\section{c) Dosificaciones y resistencias medias de los hormigones.}

Las dosificaciones medias de los hormigones figuran en la tabla núm. 10. En el hormigón colocado en el año 1956 se utilizó árido de $2 \frac{1}{2}$ pulgadas de tamaño máximo; y en el colocado en 1957 y 1958 , árido de $1 \mathrm{l} / 2$ pulgadas.

TABLA 10.-Dosificaciones medias de los hormigones de pavimento.

\begin{tabular}{|c|c|c|c|}
\hline & $\begin{array}{l}\text { Gravas de } 21 / 2 \text { pulgadas } \\
\text { Cementos alemanes }\end{array}$ & $\begin{array}{l}\text { Gravas de } 1 \% \text { pulgadas } \\
\text { Cementos alemanes }\end{array}$ & $\begin{array}{l}\text { Gravas de } 11 / 2 \text { pulgadas } \\
\text { Cemento weux Lionse }\end{array}$ \\
\hline 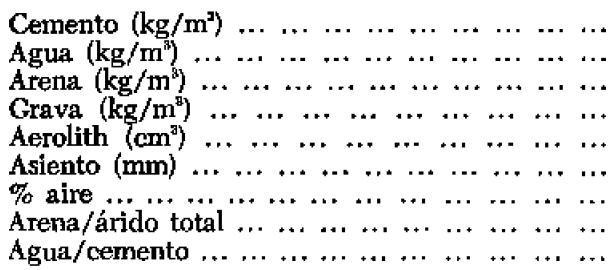 & $\begin{array}{c}388 \\
157 \\
630 \\
1.220 \\
75 \\
45 \\
3,2 \\
0,35 \\
0,40\end{array}$ & $\begin{array}{c}365 \\
159 \\
605 \\
1.260 \\
70 \\
45 \\
3,2 \\
0,33 \\
0,435\end{array}$ & $\begin{array}{r}420 \\
165 \\
570 \\
1.235 \\
100 \\
45 \\
3,2 \\
0,32 \\
0,39\end{array}$ \\
\hline
\end{tabular}


Las resistencias medias a flexión de los hormigones de la tabla núm. 10 determinadas en viguetas prismáticas tomadas en la obra y curadas en la cámara hứmeda, figuran en la tabla número 11.

TABLA 11.-Resistencias medias a flexión de los hormigones de la tabla 10, determinadas en probetas tomadas en la obra $\mathrm{y}$ curadas en la cámara húmeda a $20^{\circ} \mathrm{C}$.

DESGRIPCION DEL HORMIGON

Grava de $21 / 2$ pulgadas acementos alemanes . Grava de $1 \frac{1}{2}$ pulgadas ecementos alemanes. Grava de $1 \frac{1}{2}$ pulgadas acemento Deux Litons*

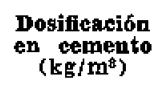

388
365
420

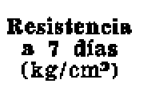

44
44,5
43,5

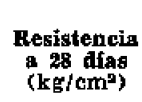

50

50,5

50,5

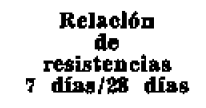

0,88

0,88

0,86

\section{d) Aumento de la resistencia del hormigón con la edad.}

El aumento medio de la resistencia del homigón de pavimento con la edad se da en la tabla número 12. Se ha tomado como referencia la resistencia a 28 días, a la que se ha dado un valor arbitrario de 100.

TABLA 12-Aumento medío con la edad de la resistencia del hormigón de pavimento. (Se ha dado un valor arbitrario de 100 a la resistencia a 28 días.)

\begin{tabular}{|c|c|c|c|c|c|}
\hline & 28 dias & 90 días & 180 días & 360 dias & J20 días \\
\hline Resistencia a flexión $\ldots \ldots \ldots \ldots \ldots$ & 100 & 111 & 113 & 115 & 116 \\
\hline Resistencia a compresión $\ldots \ldots \ldots \ldots$ & 100 & 120 & 129 & 134 & 140 \\
\hline
\end{tabular}

Se observa que, proporcionalmente, la resistencia a flexión del hormigón de pavimento aumenta bastante menos con la edad que la resistencia a compresión. En este hecho debe jugar un papel fundamental la resistencia propia del árido a flexión y a compresión.

\section{e) Relación entre las resistencias a flexión y a compresión a 28 días.}

De numerosas experiencias realizadas para relacionar las resistencias a flexión y a compresión del hormigón de pavimento, determinadas en cilindros de $6 \times 12$ pulgadas y en prismas de $6 \times 6 \times 21$ pulgadas, se ha obtenido la siguiente ecuación media:

en donde:

$$
R_{\mathrm{F}}=2,78 \mathrm{~V}_{\mathrm{c}}
$$

$R_{\text {F }}$ es la resistencia a flexión a 28 días, en $\mathrm{kg} / \mathrm{cm}^{2}$,

$R_{\text {e }}$ es la resistencia a compresión a 28 días, en $\mathrm{kg} / \mathrm{cm}^{2}$.

f) Coeftciente de variación de los resultados de resistencia y probabilidad de obtener resultados inferiores a la resistencia nominal.

Los coeficientes de variación de los resultados de resistencia de los hormigones de pavimento en función del tamaño máximo de la grava figuran en la tabla número 13.

TABLA 13,-Coeficientes de variación de los resultados de resistencia a flexión a 28 días del hormigón de pavimento. (Probetas tomadas en la obra.)

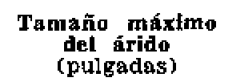

del arido
(pulgadas)

$21 / 2$

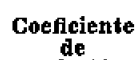

varlación

8,6
Nímero de grupos de tres probetas

utilizados en el cilculo d
ciente de variación

292 
De los valores de la tabla núm. i3 se deduce que, análogamente a como sucedió en el hormigón para estructuras corrientes, el coeficiente de variación aumenta con el tamaño de la grava. Sin embargo, a igualdad de tamaño de grava, el coeficiente de variación del hormigón de pavimento fue menor que el del hormigón para estructuras corrientes, lo que se explica porque esie hormigón, amasado en los «camiones hormigonera», tuvo más motivos de «variación» que el de pavimento. La inspección tampoco fue tan constante.

De los valores de la tabla núm. 11 se deduce que, al eliminar la grava de 2 1/2 pulgadas y sustituirla por la de $1 \mathrm{l} / 2$ pulgadas, el hormigón experimentó un notable aumento de resistencia que permitió un ahorro sustancial de cemento, además de otras ventajas, como mayor docilidad del hormigón y menor desgaste del equipo. El coeficiente de variación disminuyó también sensiblemente.

En la iabla núm. 14 se da la probabilidad de obtener resultados inferiores a la resistencia exigida de $45,5 \mathrm{~kg} / \mathrm{cm}^{2}$ a 28 días.

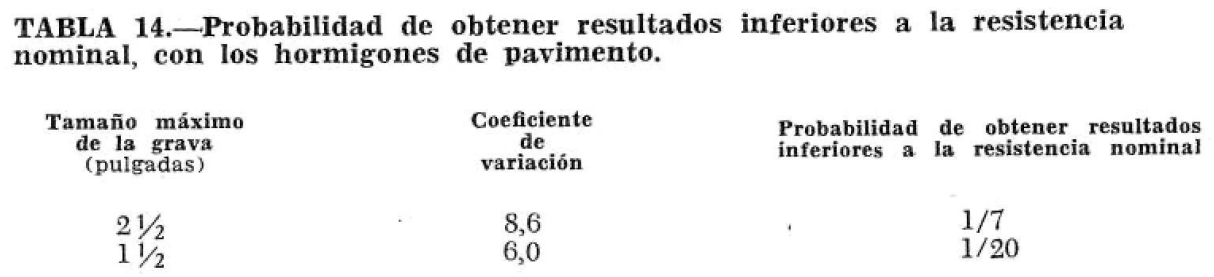

A igualdad de probabilidad de obtener resultados inferiores a la resistencia nominal, el cambio de grava de $2 \mathrm{r} / 2$ pulgadas por la de $1 \frac{1 / 2}{2}$ hubiera supuesto un ahorro de cemento de aproximadamente 10 por 100 , que es la suma del 6 por 100 debido al aumento de resistencia producido por el cambio del árido grueso, y 4 por 100 debido a la mayor homogeneidad del hormigón.

Los hormigones de pavimento, amasados en el laboratorio, dieron por término medio 7 por 100 más de resistencia que en la obra.

A continuación se detallan las experiencias realizadas para tratar de averiguar las causas por las cuales al sustituir el árido grueso de $2 \mathrm{r} / 2$ pulgadas por otro de igual naturaleza, pero de menor tamaño, el hormigón de pavimento aumentó su resistencia a la flexión.

\section{Determinación del tamaño máximo óptimo de árido para la fabri- cación del hormigón de pavimento del aeropuerto}

\section{a) Generalidades.}

Los resultados del estudio anterior, mostraron que al sustituir la grava de $2 \mathrm{I} / 2$ pulgadas de tamaño máximo en el hormigón de pavimento, por grava de $11 / 2$ pulgadas, obtenida a partir de la misma roca madre, se pudo rebajar en 6 por 100 la riqueza en cemento del hormigón, obteniéndose la misma resistencia a flexión y mayor docilidad y seguridad.

Este hecho, al menos aparentemente, está en oposición con el criterio general de que, al aumentar el tamaño del árido grueso del hormigón, aumenta su resistencia, si se conserva la dosificación en cemento. Los resultados de este trabajo están de acuerdo con dicho criterio si el factor determinante de la resistencia del conjunto es el mortero, pero no si lo es la resistencia propia de la grava o la adherencia de la grava con el mortero. Si el hormigón se ensaya a compresión, la naturaleza de la grava o la adherencia de la grava con el mortero son, en general, factores menos críticos que cuando el hormigón se ensaya a flexión. Por lo cual, en la fabricación de hormigón para la construcción de pavimentos rígidos de hormigón en masa, al que se exigen resistencias mínimas a flexión de $46 \mathrm{~kg} / \mathrm{cm}^{2}$ a 28 días, se debería proseribir el uso de canto rodado. El árido grueso apropiado es la grava de machaqueo, que, por su textura y forma poliédrica, se adhiere mucho mejor al mortero. 
Por otro lado, el árido calizo, al menos el del «Berrueco», utilizado en la construcción de la Base de Rota, suele tener fisuras, especialmente las piezas de mayor tamaño, que determinan planos de mínima resistencia. Cuanto menor es el tamaño de la grava, tantas menos fisuras tiene, debido a que en la machacadora las piezas grandes parten preferentemente por los planos más débiles. Esta es, en nuestra opinión, la causa que explica la aparente oposición a la regla relativa al árido grueso anteriormente expuesta, y que, expresada en otras paiabras, es ta siguiente: la grava gruesa del «Berruecos tiene menor resistencia a la flexión que la de menor tamaño obtenida de la misma roca madre.

Por otra parte, al disminuir el tamaño de la grava, aumenta la demanda de agua del hormigón y, por lo tanto, disminuirá su resistencia, si se conserva constante la dosificación en cemento. Según esto, ha de haber un tamaño máximo de grava óptimo, que es el que tratamos de determinar.

\section{b) Condiciones de los ensayos y experiencias previas.}

Según ASTM C31-49, el lado menor de las probetas prismáticas para el ensayo de hormigón a flexión será, como mínimo, tres veces el tamaño nominal de la grava. Para los ensayos del hormigón de grava de $1 / 2$ pulgadas se utilizaron moldes prismáticos de $6 \times 6 \times 21$ pulgadas; y en los ensayos del hormigón de grava de $2 \mathrm{t} / 2$ pulgadas, moldes de $8 \times 8 \times 28$ pulgadas, al menos en las pruebas de correlación que se exponen seguidamente.

Debido a la dificultad de manejar gran número de probetas prismáticas de $8 \times 8 \times 28$ pulgadas, en los ensayos de rutina del hormigón de árido de $2 \frac{1}{2}$ pulgadas, se utilizaron moldes de $6 \times 6 \times 21$ pulgadas, separando, antes de moldear las probetas, el árido mayor de 2 pulgadas con una criba de malla cuadrada de 2 pulgadas de lado.

Para conocer la relación de resistencias del hormigón de grava de $2 \mathrm{r} / 2$ pulgadas, ensayado en vigas de $6 \times 6 \times 21$ pulgadas, cribado previamente por la malla de 2 pulgadas, y el ensayado con toda la piedra en vigas de $8 \times 8 \times 28$ pulgadas, se moldearon probetas de dichas dimensiones con hormigón de la misma amasada. La relación de resistencias a flexión a 28 días fue 1,11, por lo cual la resistencia a flexión del hormigón a 28 días se determinó en este tipo de hormigón, dividiendo la resistencia obtenida con el hormigón cribado y en probeta de $6 \times 6 \times 21$, por la constante 1,11 .

Probetas prismáticas de $6 \times 6 \times 21$ y $8 \times 8 \times 28$ pulgadas, cortadas de un pavimento construido con hormigón de grava de $21 / 2$ pulgadas, ensayadas a flexión, dieron la misma resistencia, de lo que se deduce que el aumento de la resistencia a flexión a 28 días de las probetas amasadas con hormigón cribado, se debió a la eliminación del árido mayor de 2 pulgadas.

\section{c) Experiencias para determinar el tamaño de grava óptimo.}

A continuación se detallan las experiencias realizadas para determinar el tamaño de grava óptimo, desde el punto de vista de la resistencia a flexión del hormigón y de la economía, las cuales están basadas en las consideraciones anteriores.

c1) Resistencias a flexión del hormigón de árido de $21 / 2$ pulgadas, cribado por tamices de luz de malla decreciente, ensayado en probetas prismátícas de $8 \times 8 \times 28$ pulgadas.

Con hormigón fresco de pavimento de árido de $2 \mathrm{y} / 2$ pulgadas, se moldearon prismas de $8 \times 8 \times 28$ pulgadas, con el hormigón cribado por los siguientes tamices:

I. Con el hormigón original, es decir, cribado por el tamiz de 3 pulgadas.

II. Con el hormigón cribado por el tamiz de 2 pulgadas.

III. Con el hormigón cribado por el tamiz de $1 \mathrm{r} / \mathrm{\text {pulgadas. }}$

IV. Con el hormigón cribado por el tamiz de 1 pulgada.

V. Con el hormigón cribado por el tamiz de $/ 2$ pulgada.

Según esto, todos los prismas tenían de común el mortero y sólo se diferenciaban entre sí en la proporción y tamaño de la grava. 
Las resistencias a flexión del hormigón en función de la edad y de la luz de malla figuran en la tabla núm. 15.

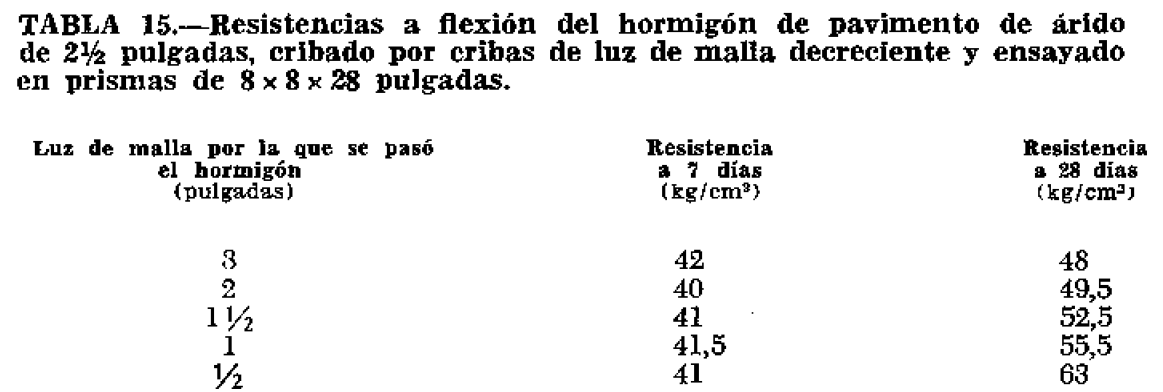

Los resultados de la tabla núm. 15 muestran que, mientras a 7 días las resistencias a flexión fueron independientes de la proporción y tamaño de la grava del hormigón, a 28 días fueron tanto más elevadas, cuanto menor era la proporción de grava y su tamaño. Lo que indica claramente que, mientras a 7 días el mortero era más débil que la grava (en los ensayos de 7 días no partía la grava), a 28 días el mortero tenía una resistencia a Hexión superior a la grava. En los ensayos a 28 días partía limpiamente la grava.

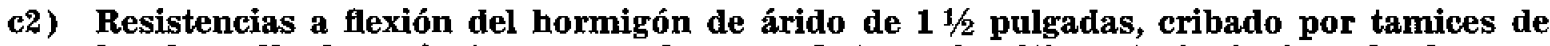
luz de malla decreciente y ensayado en probetas prismáticas de $6 \times 6 \times 21$ pulgadas.

Con hormigón de árido de $1 / 2$ pulgadas y 6 por 100 menos de cemento que en el caso anterior, se repitieron las experiencias realizadas con el hormigón de árido de $2 \%$ pulgadas, utilizándose moldes de $6 \times 6 \times 21$ pulgadas.

Las resistencias a flexión alcanzadas figuran en la tabla núm. 16.

\begin{tabular}{|c|c|c|}
\hline $\begin{array}{c}\text { Lux de malla por la que se pasó } \\
\text { el hormigón fresco } \\
\text { (pulgadas) }\end{array}$ & $\begin{array}{l}\text { Resistenoja } \\
\text { a } 7 \text { días } \\
\left(\mathbf{k g} / \mathrm{cm}^{2}\right)\end{array}$ & $\begin{array}{l}\text { Fesigtenoia } \\
\text { a } 28 \text { dias } \\
\left(\mathrm{kg} / \mathrm{cm}^{2}\right)\end{array}$ \\
\hline $\begin{array}{l}11 / 2 \\
1 \\
1 / 2\end{array}$ & $\begin{array}{l}44 \\
44 \\
44\end{array}$ & $\begin{array}{l}48 \\
48 \\
48,3\end{array}$ \\
\hline
\end{tabular}

Los resultados de la tabla núm. 16 indican que, tanto a 7 como a 28 días, la resistencia a flexión del hormigón fue independiente de la grava, lo que indica que el mortero era más débil y era, por tanto, el factor determinante de la resistencia.

c3) Se arnasaron en el laboratorio hormigones «paralelos» de $11 / 2$ y $3 / 4$ de pulgadas, respectivamente, de taman̄o máximo, con la misma riqueza en cemento $\left(363 \mathrm{~kg} / \mathrm{m}^{3}\right)$, el mismo asiento (2 pulgadas), y el mismo contenido de aire $(3,2$ por 100$)$.

La resistencia a tlexión del hormigón de árido de 1 1/2 pulgadas fue 6 por 100 más elevada a 28 días que la del hormigón de árido de $3 / 4$ de pulgada, debido a la mayor demanda de agua de este hormigón.

De las experiencias citadas se deduce lo siguiente:

1) El tamaño máximo óptimo de la grava para el hormigón de pavimento amasado con grava del «errueco» fue $1 \%$ pulgadas. 
2) El mortero del hormigón de árido de $2 \frac{1}{2}$ pulgadas era demasiado rico en relación con la calidad de la grava utilizada, es decir, la resistencia a flexión del mortero a 28 días era mayor que la de la grava.

3) El mortero del hormigón de árido de $1 \frac{1}{2}$ pulgadas tenía una resistencia a flexión igual o menor que la grava, lo que produjo una economía importante de cemento en relación con el hormigón de árido de $2 \mathrm{1} / 2$ pulgadas.

4) A igualdad de riqueza en cemento, el hormigón de árido de $3 / 4$ de pulgada de tamaño máximo dio menor resistencia a flexión que el de árido de $11 / 2$ pulgadas, por su mayor demanda de agua.

\section{d) Sugerencia.}

Las experiencias anteriores apoyan la idea de que el método de control de hormigón en obra, consistente en separar, mediante cribado, el mortero del hormigón fresco (que de antemano tiene la docilidad necesaria para su correcta puesta en obra con los medios de que se dispone) y ensayarle en probetas de dimensiones reducidas, en aparatos muy sencillos, como, por ejemplo, el del profesor Bolomey, puede ser muy práctico y representativo, si en ensayos previos de laboratorio se ha comprobado que el factor determinante de la resistencia del hormigón es el mortero.

Esta condición se cumple, en general, cuando en la fabricación del hormigón se emplean buenos áridos y buenos cementos portland, de bajo contenido en cal libre, con expansiones en el ensayo de autoclave no superiores al 0,5 por ciento.

\section{Hormigones para la construcción del puerto}

\section{a) Generalidades.}

A continuación se dan las características medias de los hormigones utilizados en la construcción del puerto de la Base de Rota. El volumen de hormigón correspondiente a este grupo fue superior a $200.000 \mathrm{~m}^{3}$; se empleó, principalmente, en la construcción del muro de coronación del dique de abrigo, en los bloques de 25 a $120 \mathrm{t}$ del muelle de atraque marginal y en el morro del rompeolas, en el manto de tetrápodos de 8,16 y 25 t, galería de servicios del muelle de atraque marginal y en dos muelles de atraque sobre pilotes de acero, protegidos por «camisas» de hormigón. El subcontratista encargado de realizar las obras fue la empresa mixta de construcción Corbelta-Coviles.

Prácticamente, todo el hormigón fue dosificado por pesada y amasado en una estacićn central de hormigonado, 'que disponía de dos hormigoneras, con capacidad para amasar $11 / 2 \mathrm{~m}^{3}$ cada una. Las hormigoneras descargaban sobre camiones volquetes con caja metálica diseñada para el transporte y vertido del hormigón fresco.

Todo el hormigón se fabricó con cemento portland, puzolana «Pucaton» de las Islas Canarias y el agente plastificante-retardador «Pozzolith».

El cemento portland debía cumplir con uno de los dos Pliegos de Condiciones ya citados anteriormente, y la mezcla de cemento y puzolana con las «Federal Specification SS-C-208 b».

La puzolana utilizada fue una toba volcánica pardo-amarillenta de las Islas Canarias. Se exigió a la puzolana una finura del 12 por 100 de residuo como máximo sobre el tamiz núm. 325 de la serie ASTM.

Se permitió utilizar hormigón ciclópeo en el muro de coronación y en los bloques con un peso mínimo de $25 \mathrm{t}$, pero no se ha utilizado este sistema en la obra. 
Las especificaciones para el hormigón del puerto y el agente plastificante-retardador se dan en el apéndice III.

\section{b) Características fisicoquímicas medias de los cementos y de la puzolana utilizados en el hormigón.}

En la fabricación del hormigón del puerto se han utilizado, casi exclusivamente, dos cementos portland de características algo diferentes. Uno de endurecimiento más lento, que llamaremos (S), y otro más rápido que llamaremos $(F)$. El hormigón del segundo pantalán se fabricó casi exclusivamente con cemento portland $(F)$ y el del resto de la obra indistintamente con uno $u$ otro.

Las características fisicoquímicas de estos dos cementos se dan en la tabla núm. 17.

TABLA 17.-Características fisiconuimicas medias de los cementos portland (F) y (S), utilizados en la fabricación del hormigón del puerto.

\section{$\underset{12-1947}{\text { Normag. }}$ S.}

Sílioe

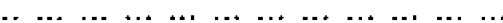

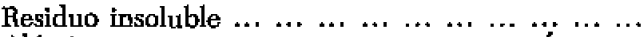

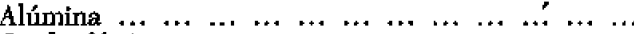

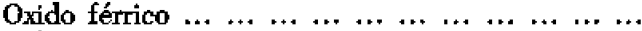

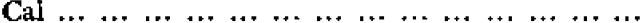

$\begin{array}{lllllllllllll}\text { Magnesia } & \ldots & \ldots & \ldots & \ldots & \ldots & \ldots & \ldots & \ldots & \ldots & \ldots & \ldots & \ldots\end{array}$

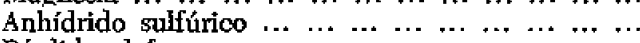

Pérdida al fuego $\ldots \ldots \ldots \ldots \ldots$

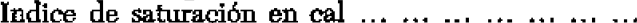

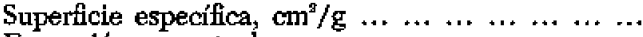

Expansión en autoclave $\ldots \ldots \ldots \ldots \ldots \ldots$

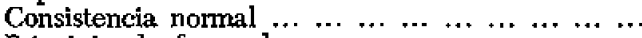

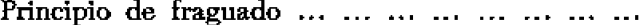

Final de fraguado $\ldots \ldots \ldots \ldots \ldots \ldots$

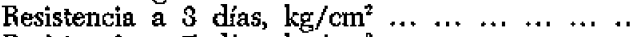

Resistencia a 7 días, $\mathrm{kg} / \mathrm{cm}^{2}$
Cemento (F)

21,3

0,8
5,8

2,9

64,0

1,1

1,7

0,92

3.500

0,25
27,00

2 h. $40^{\circ}$

$4 \mathrm{~h}$.

364
Gemento (\$)

22,2
0,6
3,2
3,6
64,8
0,7
1,2
2,9
0,94
3.110
0,05
26,00
$2 \mathrm{~h} .50$
$4 \mathrm{~h} .30$
180
274

En la tabla núm. 18 se dan algunas características de la puzolana.

TABLA 18. - Características fissicoquímicas de la puzolana Pucaton.

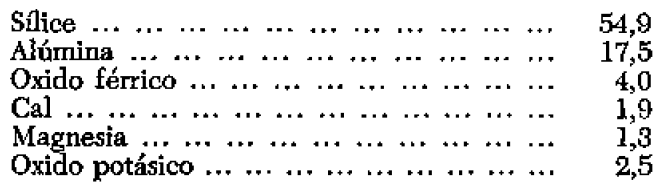

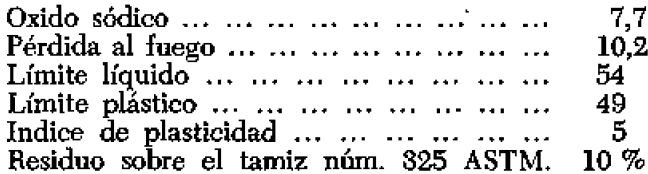

\section{c) Dosificaciones y resistencias medias del hormigón.}

Las dosificaciones medias de los hormigones empleados en la construcción del puerto figuran en la tabla núm. 19.

TABLA 19.-Dosfficaciones medias de los hormigones del puerto, en $\mathbf{k g} / \mathbf{m}^{3}$.
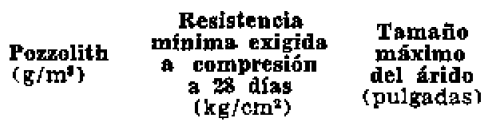

Maximo
gsiento
(pulgadas

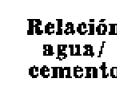

$$
\begin{aligned}
& 3 / 4 \\
& 3 / 4 \\
& 11 / 2 \\
& 21 / 2 \\
& 6 \\
& 11 / 2
\end{aligned}
$$$$
211
$$

245
245
245
245
245
211

$3 / 4$
$3 / 4$
$11 / 2$
$21 / 2$
6
$11 / 2$

$\begin{array}{cc}4 & 0,45 \\ \mathbf{5} & 0,45 \\ 4 & 0,45 \\ 4 & 0,45 \\ 31 / 2 & 0,45 \\ \mathbf{4} & 0,55\end{array}$

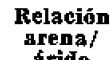

tridia

(rolumen)

Cemento

(Koimto Puzolang

$\underset{\left(\mathbf{k g} / \mathbf{m}^{\mathrm{B}}\right)}{\operatorname{Pazh}}$

Agua

$\underset{(\operatorname{cona}}{\left(\mathrm{m}^{8}\right)}$

$\underset{\left(\mathrm{kg} / \mathrm{m}^{\prime}\right)}{\text { Grave }}$

$0,40 \quad 348$

0,40

0,33

0,275

0,225

0,37

$$
\begin{aligned}
& 348 \\
& 359 \\
& 336 \\
& 334 \\
& 260 \\
& 269
\end{aligned}
$$

$\%$


Todo el hormigón, a excepción del de tetrápodos, se dosificó con un 2,6 por 1.000 de plastificante «Pozzolith», referido al peso de cemento portland más puzolana. El motivo de no añadir «Pozzolith» al hormigón de tetrápodos fue el poder desmoldar a las 24 horas, para poder volver a utilizar inmediatamente los moldes metálicos.

Las resistencias medias a compresión de los hormigones de la tabla núm. 19, determinadas en probetas cilíndricas de $6 \times 12$ pulgadas, tomadas en la obra y curadas en cámara húmeda a $20^{\circ} \mathrm{C}$, se encuentran en la tabla núm. 20 . Cuando el árido era de tamaño mayor de 2 pulgadas, antes de moldear las probetas, se cribó el hormigón por el tamiz de 2 pulgadas de luz de malla cuadrada.

TABLA 20.-Resistencias medias a compresión de los hormigones del puerto, determinadas en probetas tomadas en la obra.

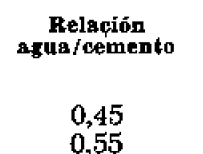

0.55
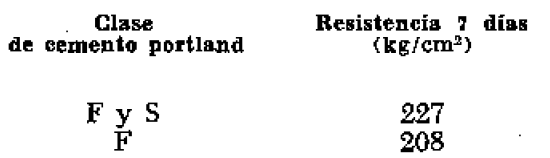

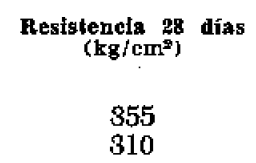

310

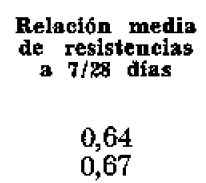

0,67

Todos los hormigones de la tabla núm. 19, de igưal relación agua/cemento, dieron prácticamente la misma resistencia; por ello se han reunido todos los valores en un resultado medio.

\section{d) Coeficientes de variación de los resultados de resistencia.}

Los coeficientes de variación de los hormigones del puerto en función del tamaño máximo del árido se dan en la tabla núm. 21.

TABLA 21.-Coeficientes de variación de los resultados de resistencia a compresión a 28 dfas de los hormigones del puerto. (Probetas tomadas en obra.)

Tamaño málmo
del arido
(pujgadas)
$3 / 4$
$1 \frac{1 / 2}{2} 6$

$\begin{gathered}\text { Coeficjente } \\ \text { de } \\ \text { variación }\end{gathered}$

$5,3 \%$
$6,1 \%$
$7,1 \%$

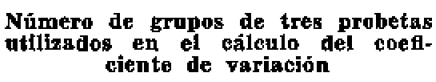

23

19

\section{e) Condición determinante de la dosificación del hormigón.}

De los resultados anteriores se deduce que todos los hormigones del puerto dieron resistencias muy superiores a la resistencia nominal, por lo que bajo este aspecto se hubiera podido disminuir la dosificación de cemento y puzolana, pero entonces el hormigón no habría cumplido con la condición de recepción que fija relaciones agua/cemento máximás, que ha sido, por tanto, la condición determinante de la dosificación.

Sin duda, se ha fijado una relación agua/cemento tan baja $(0,45)$ en los hormigones del puerto, así como el uso obligatorio de puzolana, por un criterio de durabilidad del hormigón frente al ataque químico del agua del mar.

El uso obligatorio de un plastificante-retardador en los hormigones, se debe, probablemente, a que, mediante su uso, se rebaja la demanda de agua y se regula el desarrollo del calor de fraguado del hormigón en masa, todo lo cual facilita la obtención de hormigones más impermeables, densos y duraderos. 


\section{Hormigón para viguetas pretensadas}

\section{a) Generalidades.}

Durante la segunda fase de construcción de las «viviendas familiares» de la Base de Rota, se fabricaron más de $80 \mathrm{~km}$ de viguetas pretensadas a pie de obra. La fabricación fue realizada por la empresa española Entrecanales y Távora, con la colaboración de Preload.

A continuación se describe la fabricación y las características del hormigón y de las viguetas.

\section{b) Fabricación de las viguetas.}

Las viguetas se fabricaron en un «patio» de hormigón en masa construido al efecto, de unos 100 metros de longitud, con testeros de hormigón armado en los extremos, fuertemente anclados, para tesar, con ayuda de un gato hidráulico, los alambres de acero que posteriormente transmitirían su tensión al hormigón de las viguetas, comprimiéndole, merced a la adherencia entre el hormigón endurecido y el acero. El patio estaba dividido en tres franjas longitudinales o «cunas», en cada una de las cuales se podían moldear cuatro hileras de viguetas, de unos $90 \mathrm{~m}$ de longitud. Diariamente se hormigonaban las viguetas correspondientes a uni «cuna», se desencofraban los costeros de otra, y se cortaban los alambres de la tercera, y, por lo tanto, se pudieron obtener $360 \mathrm{~m}$ diarios de viguetas. Los encofrados consistían en costeros metálicos. Se utilizaron separadores dobles independientes entre las viguetas de cada hilera. Se daba a los alambres un tesado simultáneo iricial del 80 por 100 de la tensión máxima de rotura, o sea:

$$
0,80 \times 180=144 \mathrm{~kg} / \mathrm{mm}^{2}
$$

La elongación correspondiente a una tensión de $144 \mathrm{~kg} / \mathrm{mm}^{2}$, en alambres de $91,4 \mathrm{~m}$ de longilud, es:

$$
9.140 \times \frac{14.400}{2.165 .000}=60,7 \mathrm{~cm}
$$

Se debe utilizar un sistema de medida directa para determinar el esfuerzo introducido durante el tesado, por ejemplo, un dinamónetro o un manómetro adaptado al gato hidxáulico; sin embargo, durante todo el período de fabricación se utilizó la medida de la elongación como medida de la tensión inicial aplicada. El método dio buen resultado, pero requiere una inspección muy estrecha.

El hormigón se dosificó por pesada, y se amasó en una hormigonera corriente de eje horizontal. El volumen de cada amasada fue de 55 litros, y el tiempo de amasado de 1 1 12 minutos. El hormigón fresco se vertía lo antes posible entre los costeros metálicos, que se vibraban y transmitían la vibración al hormigón. Entre los costeros y el pavimento se colocaron juntas de goma.

Se desencofraba de 10 a $14 \mathrm{hr}$ después del hormigonado y se cortaban los alambres y trasladaban las viguetas a las $60 \mathrm{hr}$. Durante este tiempo se mantenía el hormigón húmedo y, posteriormente, se debía continuar el cuado con agua hasta los 10 días. La fabricación de las viguetas se realizó sin curado especial y sin ayuda de acelerantes químicos.

Frecuentemente, antes de cortar alambres, apareció una grieta en las viguetas en la proximidad de las juntas del pavimento y que desaparecían en el momento de cortar los alambres. Muy probablemente eran producidas por movimientos verticales deí pavimento debido a diferencias periódicas de humedad y de temperatura.

Para prevenir un posible efecto de corrosión del acero, se prohibió el empleo de compuestos ace. lerantes que tuvieran cloruros. 


\section{c) Características de los materiales utilizados en la fabricación de las viguetas.}

Las especificaciones del hormigón y de los alambres de acero para la fabricación de las viguetas se hallan en el apéndice IV.

En la fabricación de las viguetas se utilizaron dos clases de cemento portland, el danés «Aalborg» y el yugoslavo «Deux Lions».

Las características fisicoquímicas del cemento «Deux Lions» se dan en la tabla núm. 26.

Con ambos cementos se obtuvieron hormigones de elevadas resistencias iniciales, mientras los granos de cemento se mantuvieron «sueltos», sin el menor síntoma de humedad. Para este objeto, es de la mayor importancia que los cementos sean recientes y se almacenen en lugares donde estén perfectamente resguardados de la humedad.

Los áridos utilizados fueron los siguientes:

Gravilla--Se empleó como árido grueso gravilla de machaqueo, dura, de color oscuro. Se utilizó la fracción que pasó por la criba de $10 \mathrm{~mm}$ y quedó retenida por la de $5 \mathrm{~mm}$, sin ser completa la separación.

Peso específico (saturado, superficie seca) $=2,73$

Absorción .......................... $=0,75$

El tamaño máximo del árido grueso no debía ser superior a $1 / 3$ del mínimo espesor de la viga.

Arena.-En la primera mitad de la fabricación se utilizó como árido fino arena de playa lavada, que procedía de una instalación de obtención de «garbancillo».

La granulometría de la arena de playa lavada fue la siguiente:

$\begin{array}{ccccccc}\text { TAMIZ NUMERO } & \mathbf{4} & \mathbf{8} & \mathbf{1 6} & \mathbf{8 0} & & \mathbf{5 0} \\ & 100 & 75 & 50 & 30 & 15 & 1\end{array}$

Módulo de finura $=3,30$. Peso especifico (saturado, superficie seca) $=2,59$. Absorción $=0,95$.

Posteriormente se mezcló 70 por 100 de arena de playa lavada con 30 por 100 de arena de machaqueo, procedente de la obtención de gravilla para las viguetas. La granulometría de la mezcla fue la siguiente:

TAMI

\begin{tabular}{|c|c|c|c|c|c|c|}
\hline $3 / 8^{\prime \prime}$ & Nûm. 4 & Nfím. 8 & Num, 16 & Nüm. 30 & Núm. 50 & Núm. 100 \\
\hline 100 & 99 & 73 & 49 & 38 & 16 & 6 \\
\hline
\end{tabular}

Módulo de finura $=3,25$.

En la fabricación de las viguetas se utilizaron alambres de acero de $4 \mathrm{~mm}$ de diámetro, con la superficie ligeramente rugosa y desengrasada, de calidad «cold drawn high carbon steel», fabricados por la «British Ropes Li».

Las características mecánicas de los alambres figuran en la tabla nứm. 22:

TABLA 22--Características mecánicas de los alambres de acero de las viguetas pretensadas.

\begin{tabular}{|c|c|c|}
\hline & & Especiflaciones \\
\hline 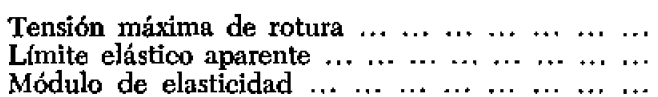 & $\begin{array}{r}175 \text { a } 190 \mathrm{~kg} / \mathrm{mm}^{2} \\
167 \mathrm{~kg} / \mathrm{mm}^{2} \\
2.165 .000 \mathrm{~kg} / \mathrm{cm}^{2}\end{array}$ & $\begin{array}{l}\text { Min. } 160 \mathrm{~kg} / \mathrm{mm}^{2} \\
\text { Min. } 153 \mathrm{~kg} / \mathrm{mm}^{2}\end{array}$ \\
\hline
\end{tabular}




\section{d) Dosificación y resistencias medias del hormigôn.}

La dosificación media y las resistencias del hormigón utilizado en la fabricación de las viguetas se dan en la tabla núm. 23 . Las probetas cilindrícas de control de $6 \times 12$ pulgadas se conservaron al aire libre, regándolas de vez en cuando. Se moldearon, vibrando los moldes metálicos con el mismo vibrador manual utilizado en la fabricación de las viguetas. Antes de proceder a la rotura se determinaba la densidad de las probetas, que debía ser similar a la del hormigón de las viguetas. La densidad de las viguetas, después de deducir el efecto de los alambres de acero, fue 2,46 .

TABLA 23.-Dosiflcación y resistencias del hormigón utilizado en la fabricación de las viguetas pretensadas. (Probetas conservadas al aire Hbre, con algún riego).

\begin{tabular}{|c|c|c|c|c|c|}
\hline & & & $\begin{array}{c}\text { Resistencia } \\
\text { a } 60 \text { horas } \\
\left(\mathrm{x} / \mathrm{cm}^{2}\right)\end{array}$ & $\begin{array}{c}\text { Resisteneia } \\
\text { a } 7 \text { difas } \\
\left(\mathrm{kg} / \mathrm{cm}^{2}\right)\end{array}$ & $\begin{array}{c}\text { Resistencia } \\
\text { a } 28 \text { digs } \\
\left(\mathrm{kg} / \mathrm{cm}^{2}\right)\end{array}$ \\
\hline 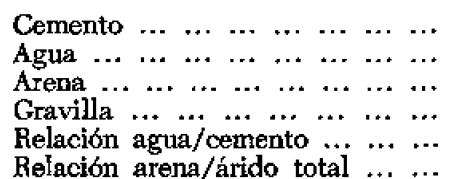 & $\begin{array}{l}475 \\
180 \\
820 \\
970 \\
0,38 \\
0,47\end{array}$ & $\begin{array}{l}\mathrm{kg} / \mathrm{m}^{3} \\
\mathrm{~kg} / \mathrm{m}^{3} \\
\mathrm{~kg} / \mathrm{m}^{2} \\
\mathrm{~kg} / \mathrm{m}^{\mathrm{s}}\end{array}$ & 280 & 400 & 530 \\
\hline
\end{tabular}

El asiento medio del hormigón fresco, recién descargado de la hormigonera, fue próximo a $1 \mathrm{~cm}$, medido en el cono de Abrams.

En este sistema (Hoyer) de fabricación de viguetas, de anclaje por adherencia, es fundamental que el hormigón «cierre» perfectamente, para que el contacto con los alambres $y$, por tanto, la adherencia, sea lo más elevada posible.

\section{e) Características y ensayos de las viguetas.}

La sección de hormigón de las viguetas fue constante en todos los casos, con perfil simétrico doble T. Las características de la sección fueron las siguientes:

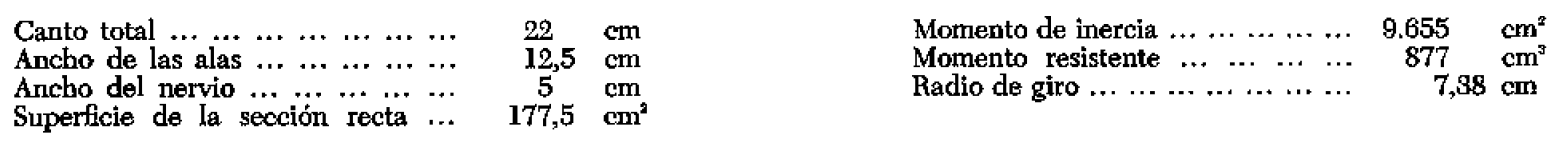

La longitud de las viguetas fue muy variada: desde $1 \mathrm{~m}$ hasta algo más de 6 metros.

El número de alambres por vigueta varió desde 4 hasta 11, según los distintos modelos. No se utilizaron cercos.

En las figuras I y II se representa la sección de dos viguetas de 9 y 10 alambres. La vigueta I está proyectada para soportar un momento máximo de trabajo de $+1.090 \mathrm{~m} / \mathrm{kg}$, y la vigueta II : $+895 \mathrm{~m} / \mathrm{kg}$ y $-300 \mathrm{~m} / \mathrm{kg}$.

La excentricidad de los alambres de la vigueta I es $e=4,05 \mathrm{~cm}$, y la de la vigueta II, $e=2,46$ centímetros.

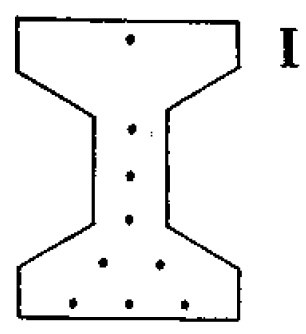

El recubrimiento mínimo de los alambres fue de 2 centímetros.

De las viguetas fabricadas durante una semana bajo inspección continuada, se separaba una de cada modelo para su ensayo a la edad de 10 días.

Para el ensayo de las viguetas se construyó una losa de hormigón, en el centro de la cual iba fuertemente anclado un pórtico de hierro de perfil en T. La vigueta se apoyaba en sus extremos sobre dos trípodes de acero separados por

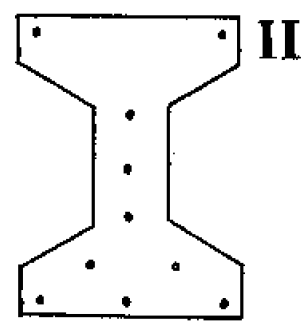


una longitud, L, y se cargana en dos puntos intermedios simétricamente situados, por medio de un gato hidráulico provisto de manómetro, hasta una carga, $P$, que produjera un momento flector máximo, $M$, igual al doble del momento flector máximo de trabajo. Con el sistema de cargas indicado. se tiene:

$$
\text { M. máx. }=\frac{P L}{6}
$$

A la vez que se cargaba la viga, se medían las flechas correspondientes y se observaba su comportamiento, aparición de grietas, etc. Las flechas medias de las viguetas I y II, durante el ensayo, al aplicarles el momento máximo de trabajo, fueron el 1,3 por 1.000 y el 1,2 por 1.000 de la luz, respectivamente.

Las viguetas soportaron sin rotura un monento igual al doble del máximo de trabajo, y se agrietaron en varios puntos poco antes de alcanzar dicha carga. Al descargar, las grietas se cerraban y no era posible distinguirlas a simple vista.

\section{Criterio aplicado para el cãlcuIo de las viguetas pretensadas.}

El criterio aplicado para el cálculo de las viguetas ha sido el del «U. S. Department of Commerce, Bureau of Public Roads, Washington», para puentes de hormigón pretensado.

Las cargas de trabajo de las viguetas en las edificaciones, expresadas en kilogramos por metro lineal de vigueta, fueron las siguientes:

$\begin{array}{cccc}\begin{array}{c}\text { Distancia } \\ \text { etre edes } \\ \text { de viguetas }\end{array} & \begin{array}{c}\text { Carga muerta } \\ (\mathrm{kgg} / \mathrm{m})\end{array} & \begin{array}{c}\text { Carga viva } \\ (\mathrm{kg} / \mathrm{m})\end{array} & \begin{array}{c}\text { Carga total } \\ (\mathrm{kg} / \mathrm{m})\end{array} \\ 0,98 \mathrm{~m} & 370 & 78 & \\ 0,65 \mathrm{~m} & 385 & 50 & 455\end{array}$

\section{f) Dificultades en la fabricación de las viguetas.}

Las principales dificultades que en alguna ocasión surgieron durante la fabricación de las viguetas, fueron las siguientes:

a) Anclaje imperfecto de algún alambre en el clavijero, lo que provocó su deslizamiento, con la pérdida consiguiente de tensión.

b) Escasa adherencia entre el hormigón y los alambres, debido a haberse empleado hormigón demasiado seco, o haber sido la vibración insuficiente.

c) Utilización de cemento con alguna humedad, lo que originó un desarrollo de resistencias más lento de lo previsto, que obligó a prolongar el período de curado en «cuna», antes de cortar alambres.

Estimamos que, para la fabricación de viguetas pretensadas, en las que la adherencia juega un papel tan crítico, el cemento portland que se utilice debe estar perfectamente clinkerizado. Debe presentar una expansión en el ensayo de autoclave inferior al 0,5 por 100 . Asimismo, no creemos recomendable utilizar cementos excesivamente finos para conseguir altas resistencias iniciales, pues ello supondría, en general, aumentar la demanda de agua del hormigón y su retracción.

\section{Hormigones para los elementos prefabricados de las viviendas familiares}

\section{a) Generalidades.}

En la segunda fase de la construcción de las «viviendas familiares» de la Base, se utilizaron como elementos prefabricados bloques huecos, bovedillas y piezas en $U$, además de las viguetas preten- 
sadas. Todos estos elementos fueron fabricados a pie de obra, por la empresa constructora Entrecanales y Távora».

Las especificaciones de los bloques «de carga» y «sencillos» se dan en el apéndice V.

Los «bloques huecos sencillos» se emplearon en los tabiques interiores de separación de las viviendas.

\section{b) Fabricación de los bloques de carga.}

Los bloques y las bovedillas se fabricaron sobre una losa de hormigón de unos $2.100 \mathrm{~m}^{2}$ de superficie, con la máquina alemana Komet $104 \mathrm{~F}$.

El hormigón, dosificado por pesada, se amasó en una hormigonera de eje horizontal (posteriormente en amasadora) en amasadas de unos 400 litros. Primero se mezclaron los áridos y el cemento durante medio minuto, luego se añadió el agua y se amasó un minuto más como mínimo.

El hormigón se descargaba sobre una tolva, de donde se vertía sobre carrillos de mano que le transportaban y descargaban en la máquina Komet de moldear bloques. Esta máquina fabrica los bloques directamente sobre el pavimento. Cuando había moldeado una serie, se trasladaba un metro hacia adelante, donde se moldeaba la siguiente serie de bloques, y así sucesivamente. El hormigón fresco se vertía en la máquina y se extendía con un rastrillo plano, se vibraba durante 1 a 2 segundos para que se acoplara la mayor parte del material en las rendijas de los moldes, se añadía el resto del material, se enrasaba y a continuación se vibraba y compactaba con un pisón hasta que el bloque tuviera la altura deseada. Normalmente, tres golpes de pisón fueron suficientes. La vibración era horizontal, y la frecuencia de 6.000 vibraciones por minuto.

Cada serie se componía de ocho bloques de $25 \times 49 \times 24 \mathrm{~cm}$. La producción, en condiciones normales, se puede estimar en 100 bloques por hora. A los 3 días de fabricados, se trasladaban los bloques a un cobertizo, en el que proseguía el curado con agua hasta los 10 días. $A$ esta edad se podían colocar en obra, después de haber sido ensayada y aprobada la producción de cada día.

\section{c) Dosificación, materiales y resistencia del hormigón y de los bloques de carga.}

En la fabricación de los bloques de carga se utilizó el cemento danés «Aalborg» y el yugoslavo «Deux Lions».

Para poder conseguir las elevadas resistencias exigidas a los bloques y que se desmoldaran inmediatamente con facilidad y sin deformación en la máquina Komet, fue necesario fabricar el hormigón con áridos de granulometría discontinua. Las granulometrías continuas ensayadas no dieron el resultado deseado.

Como árido grueso se utilizó «garbancillo», obtenido cribando con agua, gravilla y arena gruesa de playa, por cribas de 10 y $4 \mathrm{~mm}$ de luz de malla cuadrada. La arena inferior a $4 \mathrm{~mm}$, posterior mente se utilizó en la fabricación de viguetas y bovedillas. El material mayor de $10 \mathrm{~mm}$ se pasó por un molino de martillos y se volvió a cribar.

Como árido fino se utilizó arena de duna, muy abundante en aquella zona, que se extraía a unos metros de distancia de la hormigonera. 
La granulometría de los áridos fue la siguiente:

Tamlz ASTM

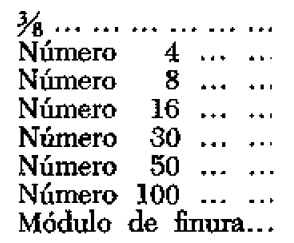

Garbancillo
$(\%$ que pasa $)$

100
40
9
7
6
3
1
5,3

Arena de duna
$(\%$ que pasa $)$

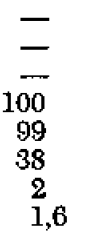

La proporción óptima de arena de duna en peso, fue el $20-21$ por 100 del árido total. Con esta proporción se consiguieron las características mecánicas exigidas y una textura rugosa de los bloques muy adecuada para su posterior enfoscado.

La dosificación media y la resistencia media de los bloques a los 10 días figuran en la tabla núm. 24 .

TABLA 24---Dosificación y resistencia media de los bloques de carga a los do días.

\begin{tabular}{|c|c|c|c|}
\hline & & ' & $\begin{array}{l}\text { Resistencia medis } \\
\text { de loo bloques } \\
\text { a log } 10 \text { diass } \\
\left.\text { ( } 1 \mathrm{rg}^{2} / \mathrm{cm}^{2}\right)\end{array}$ \\
\hline 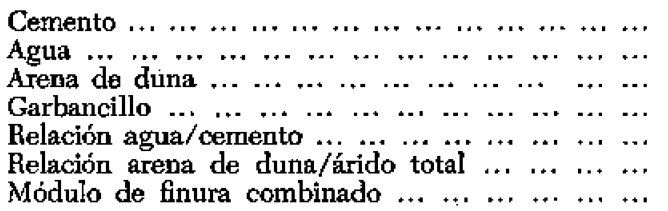 & $\begin{array}{r}225 \\
114 \\
420 \\
1.570 \\
0,51 \\
0,21 \\
4,55\end{array}$ & $\begin{array}{l}\mathrm{kg} / \mathrm{m}^{\mathrm{a}} \\
\mathrm{kg} / \mathrm{m}^{3} \\
\mathrm{~kg} / \mathrm{m}^{3} \\
\mathrm{~kg} / \mathrm{m}^{3}\end{array}$ & 60 \\
\hline
\end{tabular}

En la tabla núm. 25 pueden verse las resistencias de un hormigón similar al de la tabla núm. 24, de $250 \mathrm{~kg} / \mathrm{m}^{3}$ de cemento, ensayado en probeta cilíndrica de $6 \times 12$ pulgadas, curado en cámara a $20^{\circ} \mathrm{C}$. Las probetas se moldearon vibrando el hormigón sobre mesa vibratoria.

TABLA 25,-Resistencia en probeta cilíndrica de un hormigón de $250 \mathrm{~kg} / \mathrm{m}^{3}$ de cemento, relación agua/ cemento 0,46 y módulo de finura 4,55 .

\begin{tabular}{|c|c|c|c|c|c|}
\hline & & & $\begin{array}{l}\text { Resistenela } \\
\text { a } 7 \text { días } \\
\left(\mathrm{kg} / \mathrm{cm}^{2}\right)\end{array}$ & $\begin{array}{l}\text { Resigteneia } \\
\text { a } 28 \text { dias } \\
\left(\mathrm{kg} / \mathrm{cm}^{2}\right)\end{array}$ & 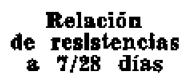 \\
\hline 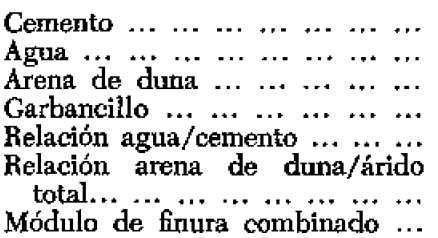 & $\begin{array}{r}250 \\
114 \\
400 \\
1.570 \\
0,46 \\
0,20 \\
4,55\end{array}$ & $\begin{array}{l}\mathrm{kg} / \mathrm{m}^{3} \\
\mathrm{~kg} / \mathrm{m}^{3} \\
\mathrm{~kg} / \mathrm{m}^{\mathrm{s}} \\
\mathrm{kg} / \mathrm{m}^{\mathrm{s}}\end{array}$ & 280 & 338 & 0,83 \\
\hline
\end{tabular}

En la elevada relación $(0,83)$ entre las resistencias a 7 días y 28 días, interviene, además de la calidad del cemento, la pequeña cantidad de agua de amasado utilizada. Este hecho explica el que la resistencia de los bloques aumentó poco a partir de los 10 días.

Cada serie de bloques de carga, moldeada por la máquina, se componía de 8 unidades de 3 tipos diferentes: 6 bloques tipo $\mathrm{A}, 1$ bloque tipo $\mathrm{B}$ y 1 bloque tipo $\mathrm{C}$.

La mitad de los bloques $\mathrm{B}$ y $\mathrm{C}$ no tenían fondo, debido a que iban a ser colocados en las esquinas de las casas y posteriormente rellenados con hormigón corriente, después de colocar en su interior una ligera armadura.

El volumen de hormigón necesario para una serie de bloques fue de 123,5 litros. 
El bloque $A$, que es el que se sometió a ensayo de rotura, tenf́a las siguientes características:

Dimensiones: $25 \times 49 \times 24 \mathrm{~cm}$.

Número de celdas: 8 .

Espesor de las paredes y tabiques: $25 \mathrm{~mm}$.

Area total de una sección media horizontal: $12,25 \mathrm{dm}^{2}$.

Area de hormigón de una sección media horizontal: $6,20 \mathrm{dm}^{2}$.

Volumen de hormigón de un bloque: $16,3 \mathrm{dm}^{3}$.

Peso de un bloque: $37 \mathrm{~kg}$.

\section{d) Acerca de la consistencia óptima del hormigón en la fabricación de bloques de carga.}

Como síntesis de las numerosas experiencias realizadas, consideramos que para conseguir bloques de elevada resistencia mecánica, sin deformación, es necesario que el cemento, los finos y el agua formen una pasta que moje, cubra y enlace perfectamente los granos de garbancillo. La «viscosidad» de la pasta ha de ser suficiente para que pueda circular entre los huecos que dejan entre sí los granos de garbancillo con el sistema de vibración adoptado y, a la vez, ha de tener cohesión suficiente para dar la rigidez necesaria al bloque y que pueda ser desmoldado inmediatamente sin que se deforme.

Con áridos de granulometría discontinua, que dejan entre los granos huecos mucho mayores que los de granulometría continua, se pueden utilizar pastas de mayor «viscosidad», que darán mayor rigidez al bloque en estado fresco, y mayor resistencia una vez endurecido.

Mientras la pasta no se adhiera perfectamente a los granos de árido, no se obtendrán bloques de alta resistencia, aunque se aumenta la riqueza en cemento. Por ello es fundamental dar al hormigón la consistencia necesaria, que, a igualdad de materiales, viene determinada por una proporción óptima de agua. Por debajo de esta proporción, la pasta es demasiado viscosa, el hormigón no «cierra» bien, el bloque tiene aspecto seco y poco peso. Por encina del óptimo, el bloque tiene poca rigidez en estado fresco y se deforma fácilmente.

Para facilitar el control de la consistencia, los áridos deben tener humedad constante. La consistencia adecuada del hormigón fresco es aquella que produce un bloque que, una vez desmoldado, presenta una superficie en la que se ve brillar la pasta, no tiene deformaciones y es denso.

\section{e) Bloques huecos sencillos.}

Los bloques huecos sencillos utilizados en la construcción de los tabiques de separación de las viviendas se fabricaron en la máquina Komet.

Las dimensiones exteriores de los bloques fueron: $12 \times 49 \times 24 \mathrm{~cm}$.

Como árido se utilizó arena gruesa de playa, de módulo de finura medio 3,3 .

Para conseguir la resistencia mínima especificada a 10 días, fue suficiente la siguiente dosificación, igual a la utilizada en la fabricación de bovedillas:

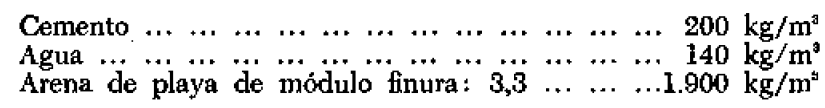

Al igual que en los bloques de carga, se debe poner el máximo cuidado en el control del agua de amasado. 


\section{f) Bovedillas.}

Las bovedillas de las viviendas familiares, al igual que los bloques, se fabricaron en la máquina Komet.

Segín el proyecto, las bovedillas en el forjado iban a soportar una carga máxima uniformemente repartida de $450 \mathrm{~kg} / \mathrm{m}^{2}$. Se consideraron satisfactorias las bovedillas que, sin presentar grietas ni defectos, apoyadas de forma similar a la de trabajo en el forjado, soportaron, sin rotura, una carga uniformemente repartida igual a tres veces la máxima de trabajo.

El mortero se fabricó en amasadora. El cemento utilizado fue «Deux Lions».

Como árido se utilizó arena de playa gruesa de módulo de finura medio 3,3 .

La granulometría media de la arena fue la siguiente:

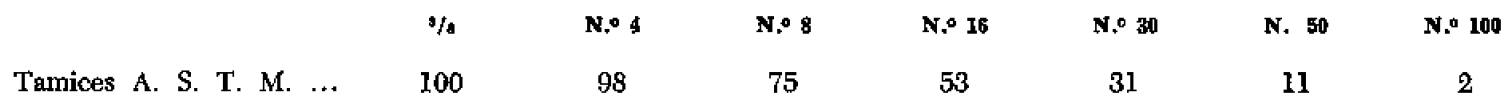

Las condiciones de fabricación de estas piezas fueron menos críticas que en el caso de los bloques. Un segundo de vibración previa en la máquina y tres golpes de pisón fueron suficientes.

La proporción óptima de agua de amasado fue la máxima con la que se obtenían las bovedillas sin deformación.

Un factor que se ha de considerar en la fabricación, es que el mortero debe caer con facilidad por las rendijas de los moldes, lo que no sucede si la humedad es muy alta.

Cada serie de fabricación se componía de 4 bovedillas. La base de las bovedillas era de $25 \times 92$ centímetros, con perfil adecuado en los extremos para encajar y apoyarse en las alas inferiores de las viguetas. $\mathrm{El}$ peso aproximado de una bovedilla fue de 33 kilogramos.

Las bovedillas se ensayaron, apoyándolas por los extremos, de una forma similar a la de trabajo en el forjado, y cargándolas con sacos de arena.

Las bovedillas fabricadas con la dosificación que se da a continuación, cumplieron con las condiciones de carga exigidas:

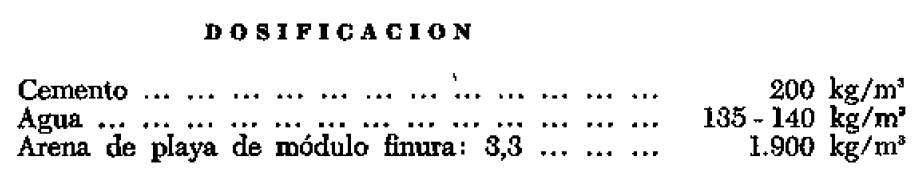

No es conveniente utilizar dosificaciones de cemento inferiores a la dada en este tipo de bovedillas de $92 \mathrm{~cm}$ de longitud, aunque cumplan con las condiciones de carga, ya que la proporción de roturas durante el transporte y colocación sería muy elevada.

Además de las bovedillas citadas, se fabricaron otras de menor tamaño, que presentaron las siguientes características:

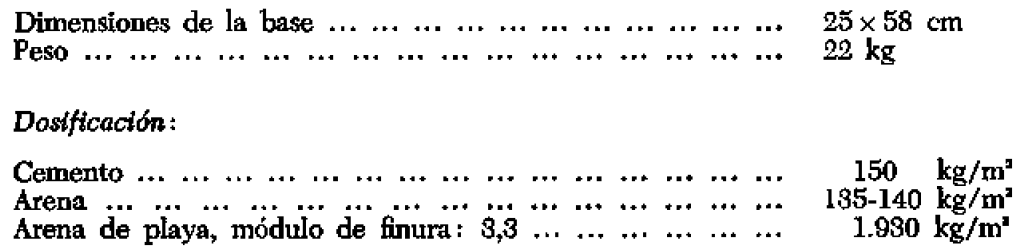




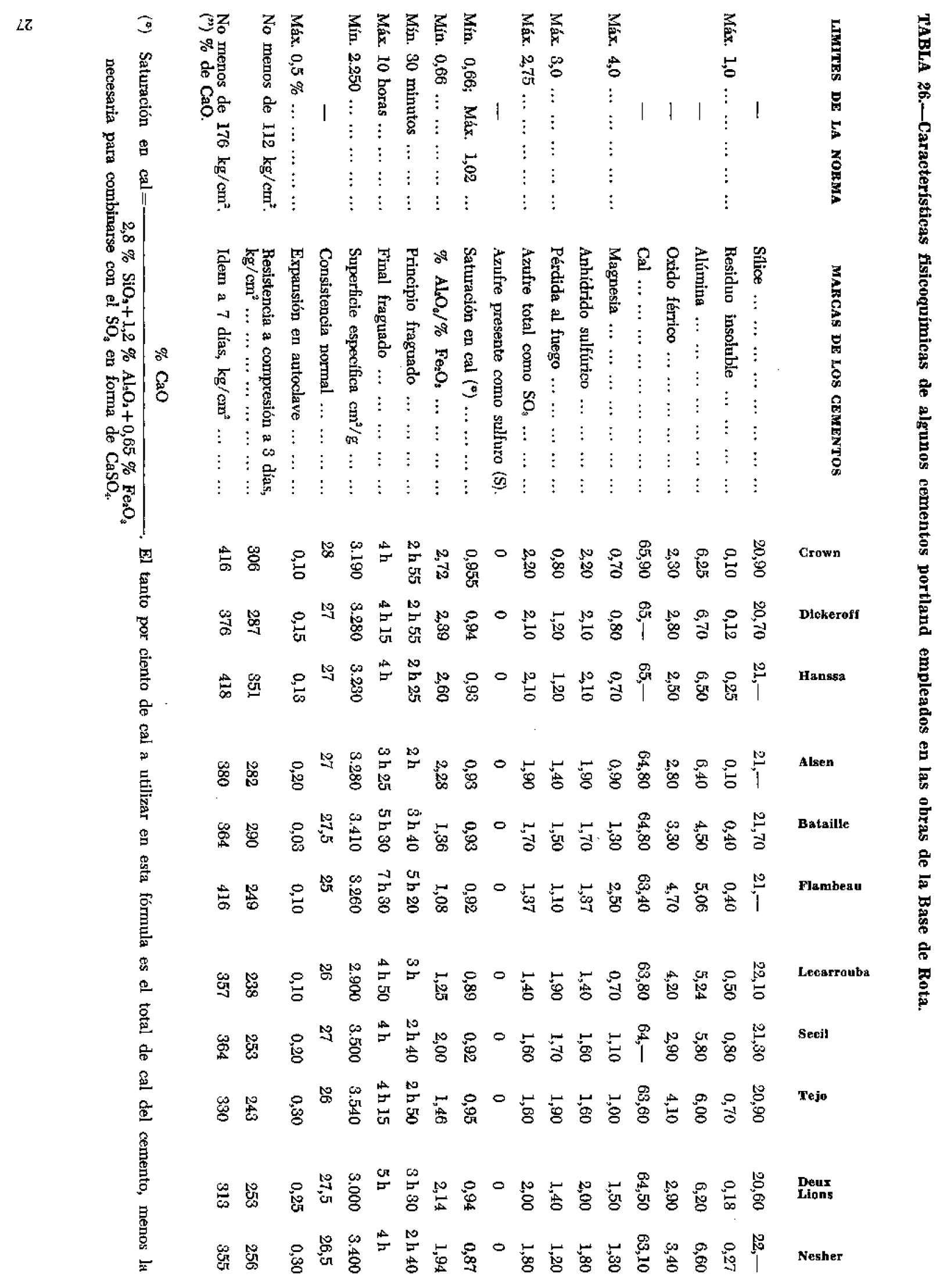




\section{Características fisicoquímicas y comportamiento en hormigón de algunos cementos de diversas procedencias}

En esta segunda parte del trabajo se pretende relacionar las propiedades fisicoquímicas de cementos portland de diversas procedencias con su comportamiento en el hormigón.

\section{a) Caracteristicas fisicoquímicas de algunos cementos portland empleados en la construc- ción de la Base de Rota.}

En la tabla núm. 26 figuran las características físicoquímicas de algunos cementos portland utilizados en las obras de la Base. En la tabla núm. 27 se han agrupado los cementos por naciones y se han tabulado sus características medias. Evidentemente, no se deben sacar de estos resultados conclusiones generales sobre Ia calidad media del cernento de cada nación, ya que el número de marcas ensayadas fue muy pequeño. Por otra parte, los cementos debían cumplir con las especificaciones citadas anteriormente.

TABLA 27.-Características fisicoquímicas medias de algunos cementos portland utilizados en la Base de Rota, agrupados por naciones.

Normas B. S. $12: 1847$

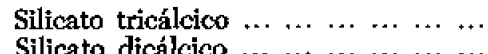

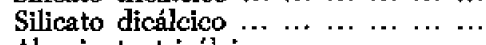

Aluminato tricálcico ...............

Ferrito aluminato tetracálcico ... ...

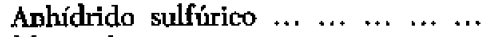

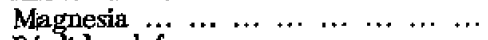

Pérdida al fuego .... .............

Residuo insoluble $\ldots \ldots \ldots \ldots \ldots$

Saturación en cal ..................

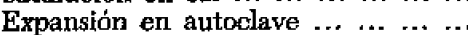

Superficie específica en $\mathrm{cm}^{2} / \mathrm{g} \ldots \ldots$

Principio de fraguado ...............

Final de fraguado $\ldots \ldots \ldots \ldots \ldots$

Consistencia normal ... ... ... ... .

Resistencia a compresión a 3 días

en $\mathrm{kg} / \mathrm{cm}^{2} \ldots \ldots \ldots \ldots \ldots$

Resistencia a compresión a 7 días,

en $\mathrm{kg} / \mathrm{cm}^{2} \ldots \ldots \ldots$

4 cermentos
alemanes

53,5
19,5
13
8
2,1
0,8
1,15
0,14
0,94
0,15
3.250
$2 \mathrm{~h} 35$
$4 \mathrm{~h}$
27

306

398

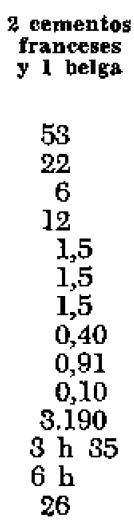

259

378

cemento
israeli

36
36
12
10,5
1,8
1,3
1,2
0,25
0,87
0,30
3.400
$2 \mathrm{~h} 40$
$4 \mathrm{~h}$
26,5

256

355

$\begin{array}{cc}\begin{array}{c}\text { 2 eementos } \\ \text { portingueses }\end{array} & \begin{array}{c}\text { 1 cemento } \\ \text { yugoslavo }\end{array} \\ & \\ 50 & 55 \\ 23 & 17,5 \\ 10 & 12,5 \\ 10,5 & 9 \\ 1,6 & 2,0 \\ 1,0 & 1,5 \\ 1,8 & 1,4 \\ 0,70 & 0,20 \\ 0,92 & 0,94 \\ 0,25 & 0,25 \\ 3.520 & 3.000 \\ 2 \mathrm{~h} 45 & 3 \mathrm{~h} 30 \\ 4 \mathrm{~h} 10 & 5 \mathrm{~h} \\ 26,5 & 27,5\end{array}$

253

316

Nota: La composición potencial de los cententos citados, se ha calculado suponiendo que toda la cal está combinada, lo cual no es exacto.

El grupo de «4 cementos alemanes», de acuerdo con los resultados de la tabla anterior, fue el que dio resistencias más elevadas en hormigón, como se verá más adelante. Estos cementos, además de tener el mayor índice de saturación en cal, deben estar muy bien clinkerizados, a juzgar por los bajos valores de la pérdida al fuego y el residuo insoluble.

El grupo de «2 cementos franceses y I belga» dio un porcentaje en silicato tricálcico tan elevado como los «4 cementos alemanes», pero el índice de saturación en cal fue más bajo y más elevados la pérdida al fuego y el residuo insoluble.

Sigue en la escala de resistencias el cemento israelí Nesher, a pesar de ser el de menor índice de saturación en cal de todos. Indudablemente, influyeron su elevada finura y su perfecta clínkerización en las elevadas resistencias desarrolladas por este cemento.

Sigue el grupo de $\ll 2$ cementos portugueses», que son los más finamente molidos. Tienen un índice de saturación en cal superior al del grupo « 2 cementos franceses y 1 belga» y al de «l cemento israelí». El menor desarrollo de resistencias de este grupo se debe, probablemente, a estar estos cementos menos completamente clinkerizados que los anteriores, como indica su mayor pérdida al fuego y su residuo insoluble. 
Sigue, finalmente, el cemento yugoslavo «Deux Lions», que tiene un índice de saturación en cal similar al del grupo «4 cementos alemanes» y también baja pérdida al fuego y residuo insoluble. Su menor desarrollo de resistencias, en relación con los otros grupos de cementos, aparentemente sólo se puede atribuir a su menor finura.

Todos los cementos citados se comportaron perfectamente en el transcurso de la obra. Como dificultades esporádicas se pueden citar las siguientes:

a) En los días calurosos de verano, uno de los eementos alemanes tuvo un fraguado demasiado rápido para ser empleado en hormigones amasados en «camiones homigonera», que a veces tienen que esperar bastante en la obra antes de la descarga.

b) Un cemento que se enviaba en barco, a granel, desde Portugal, Ilegó en ocasiones caliente a la central de hormigonado, y si por necesidades de la obra, hubo que emplearle sin tenerle ensilado hasta su normal enfriamiento, aumentaba algo la demanda de agua del hormigón, lo que dificultaba el control.

\section{b) Resistencia a compresión y demanda de agua de los hormigones amasados con los ce- mentos portland utilizados en la construcción de la Base.}

Los cementos citados anteriormente se ensayaron en hormigón. En la tabla núm. 28 figuran las resistencias medias a compresión de los hormigones correspondientes. agrupados por naciones, análogamente a como se ha hecho en la tabla núm. 27.

Con el fin de uniformar los resultados, se han extrapolado para cada cemento las resistencias correspondientes al hormigón que arbitrariamente hemos elegido como tipo de comparación, que es el de $300 \mathrm{~kg} / \mathrm{m}^{3}$ de cemento y $15 \mathrm{~cm}$ de asiento en el cono de Abrams, de las curvas experimentales «resistencia a compresión-relación agua/cemento».

Los hormigones de prueba se amasaron en el laboratorio en una hormigonera corriente de eje horizontal durante un minuto. Se moldearon probetas cilíndricas de $6 \times 12$ pulgadas, siguiendo las normas A. S. T. M., y se curaron en cámara húmeda a $20^{\circ}$ C. Los áridos utilizados fueron grava caliza de machaqueo de $20 \mathrm{~mm}$ de tamaño máximo y arena de playa mezclada con finos de machaqueo.

TABLA 28.-Resistencias medias a compresión y demanda de agua de los hormigones de 300 $\mathrm{kg} / \mathrm{m}^{\text {" }}$ de cemento y $15 \mathrm{~cm}$ de asiento, correspondientes a los grupos de cemento portland de la tabla 27.

\begin{tabular}{|c|c|c|c|c|c|}
\hline GRUPO DE CEMENTO & $\begin{array}{c}\text { Agua } \\
\text { de } \\
\text { amasado }\end{array}$ & $\begin{array}{l}\text { Resistencia } \\
\text { a } 3 \text { dias }\end{array}$ & $\begin{array}{l}\text { Resistencia } \\
\text { a } 7 \text { días }\end{array}$ & $\begin{array}{l}\text { Resistenela } \\
\text { a ds dias }\end{array}$ & $\begin{array}{l}\text { Relación } \\
\text { de registencias } \\
\text { a } 7 / 28 \text { dias }\end{array}$ \\
\hline 4 cementos alemanes $\ldots \ldots \ldots$ & 205 & 140 & 202 & 252 & 0,80 \\
\hline 2 cementos franceses y 1 belga & 205 & - & 175 & 240 & 0,73 \\
\hline 1 cemento israelí $\ldots \ldots \ldots$ & 205 & - & 170 & 230 & 0,74 \\
\hline 1 cemento yugoslavo $\ldots \ldots \ldots$ & 208 & $\ldots$ & 159 & 215 & 0,74 \\
\hline
\end{tabular}

Los resultados de la tabla núm. 28 guardan bastante buena relación con las características medias de los «grupos de cementos», dadas en la tabla núm. 27.

\section{c) Análisis y comportamiento en hormigón de otro grupo de cementos. Consideraciones.}

En la tabla núm. 29 se da el análisis medio de 6 cementos portland de calidad inferior a los cito dos anteriormente, cuyo grupo se designará $« \mathrm{~N} »$. 
TABLA 29,-Caraeteristicas físicoquímicas medias de los seis cementos portland del grupo $\alpha \mathrm{N}$ \%.

GRUPO DE CEHENTOS $\propto \mathrm{N}$.

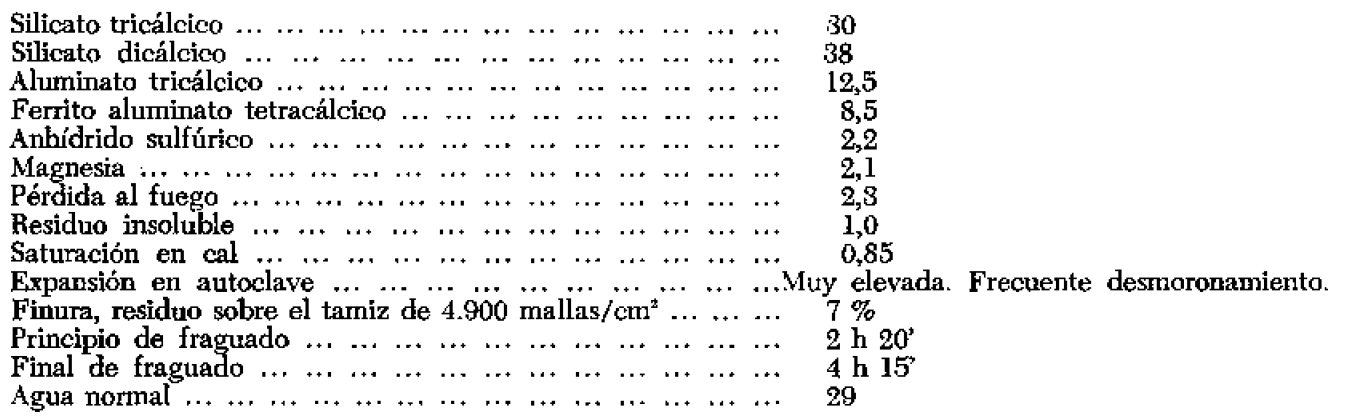

En la tabla núm. 30 figuran los resultados medios de rotura de las probetas de los hormigones correspondientes al grupo de cemento «N» que se amasaron con los mismos áridos y en las mismas condiciones que los de la tabla núm. 28.

TABLA 30.-Resistencias medias a compresión y demanda de agua de los hormigones de $300 \mathrm{~kg} / \mathrm{m}^{3}$ de cemento y $15 \mathrm{~cm}$ de asiento, correspondientes al grupo de cementos aNx.

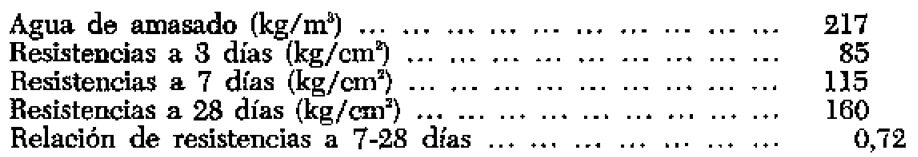

Si se comparan los resultados de la tabla núm. 30, correspondientes al hormigón medio del grupo de cementos $« \mathrm{~N} »$, con los del hormigón amasado con «un cemento yugoslavo» (véase la tabla núm. 28), se aprecia que, en condiciones semejantes, el hormigón «N» dio a 7 días el 72 por 100 de las resistencias de aquél, y el 75 por 100 a los 28 días. La demanda de agua del hormigón «N» fue, asimismo, un 5,5 por 100 más elevada.

\section{Consideraciones acerca del grupo de cementos $« \mathrm{~N}$.}

El análisis del comportamiento del grupo de cementos $« \mathrm{~N} \gg$ se ha hecho a partir de sus características fisicoquímicas, dadas en al tabla núm. 29.

El índice de saturación en cal del grupo de cementos «N» es bajo, pero también lo es el del cemento israelí Nesher, que, sin embargo, en hormigón dio 48 por 100 más de resistencia a 7 días, y 44 por 100 más a 28 días, que el hormigón medio correspondíntente al grupo «N».

En nuestra opinión, la causa fundamental de la diferencia de calidad reside en la cocción insuficiente del clínker «N», según indica su mayor pérdida al fuego y mayor residuo insoluble.

Esta opinión se ve apoyada por el hecho siguiente:

La misma fábrica que obtenía uno de los cementos del grupo «N», con las mismas materias primas y con el mismo equipo de fabricación, entiqueciendo el combustible que usaban normalmente con fuel-oil, obtuvo un cemento que, ensayado en hormigón, dio los resultados de la tabla núm. 31. 
TABLA 31.-Resistencias a compresión $y$ demanda de agua de un hormigón de $30 \mathrm{~kg}^{\mathrm{g}} / \mathrm{m}^{\mathrm{s}} \mathrm{de}$ cemento y $15 \mathrm{~cm}$ de asiento, amasado con un cemento del grupo aNs fabrieado con mejor combustible.

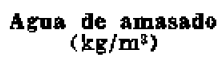

207

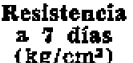

165

\section{Resistencia \\ $\left(\mathrm{kg} / \mathrm{cm}^{3}\right)$}

230

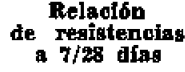

0.72

Los resultados de la tabla núm. 31 muestran que la calidad del cemento fabricado con mejor combustible es análoga a la del cemento Nesher, lo que apoya nuestra opinión de que los cementos del grupo $« \mathrm{~N} »$ estaban insuficientemente clinkerizados.

Otra conclusión es que, al mejorar la clinkerización, baja el «agua normab del cemento y, por lo tanto, la demanda de agua del hormigón, lo que mejora la calidad integral de éste.

En resumen, creemos que se puede mejorar sustancialmente la calidad de los cementos del grupo «N» de la siguiente manera:

a) Haciendo más completas las reacciones de la clinkerización.

b) Aumentando el índice de saturación en cal del clínker, a ser posible por encima de 0,90. Ahora bien, es condición previa indispensable una buena clinkerización del producto.

\section{d) Acerca del ensayo de expansión en autoclave.}

Si se observan los resultados de la tabla núm. 29, llama la atención el que los cementos del grupo «N», con dosis normales de magnesia y anhídrido sulfúrico, presenten elevada expansión en el ensayo de autoclave, mientras que los cementos de la tabla núm. 27 tienen todos expansiones reducidas. ¿No guardará relación este hecho con la clinkerización insuficiente de los cementos del grupo «N»?

En caso positivo, nos permitimos hacer las siguientes sugerencias, relacionadas con dicho ensayo:

a) El ensayo de expansión en autoclave puede ser de gran utilidad como control de fabricación.

b) En ocasiones, con el fin de mejorar la calidad de los cementos, se ha aumentado notablemente su finura de molido. En nuestra opinión, sería preferible para el usuario, que la finura se conservara próxima a los $3.300 \mathrm{~cm}^{2} / \mathrm{g}$, pero que la «expansión en autoclave» no fuera mayor del 0,5 por 100 .

c) La comparación de dos cementos por sus resistencias en mortero normal, aún a igualdad de consistencia, favorece al peor clinkerizado, ya que la relación de resistencias entre ambos sería más elevada en hormigón, debido a que la adherencia del mortero con el árido grueso es menor y la fisuración mayor en el caso de los cementos peor clinkerizados. Sin embargo, se podría utilizar la resistencia en mortero normal, como índice de calidad, si el cemento diera, en el ensayo de expansión en autoclave, una expansión no mayor del 0,5 por 100 . 


\section{Hormigones para estructuras corrientes}

1. El asiento estará comprendido entre 2 y 6 pulgadas.

(Dado que estos límites son muy amplios, el laboratorio recomendó emplear, según las condiciones del elemento a hormigonar, límites de consistencia más estrechos; a saber: de 2 a 4 y de 4 a 6 pulgadas para los hormigones con grava de $3 / 4$ de pulgada de tamaño máximo, y de 2 a 3 y de 3 a 4 pulgadas para los hormigones con grava de $1 \frac{1}{2}$ pulgadas.)

En los hormigones «aireados» el asiento no bajará de 2 pulgadas ni pasará de 4.

2. La rẹsistencia a compresión del hormigón a 28 días, determinada en gxupos de 3 probetas cilíndricas de $6 \times 12$ pulgadas, curadas en cámara húmeda a $20^{\circ} \mathrm{C}_{1}$ no bajará en ningún caso de la resistencia nominal.

(En los edificios la resistencia nominal del hormigón nunca fue menor de $176 \mathrm{~kg} / \mathrm{cm}^{2}$, y fue frecuente la ulilización de hormigones de $210 \mathrm{~kg} / \mathrm{cm}^{2}$ de resistencia nominal.)

3. Las telaciones agua/cemento de los hormigones, en función de las resistencias nominales, no sobrepasarán los siguientes valores:
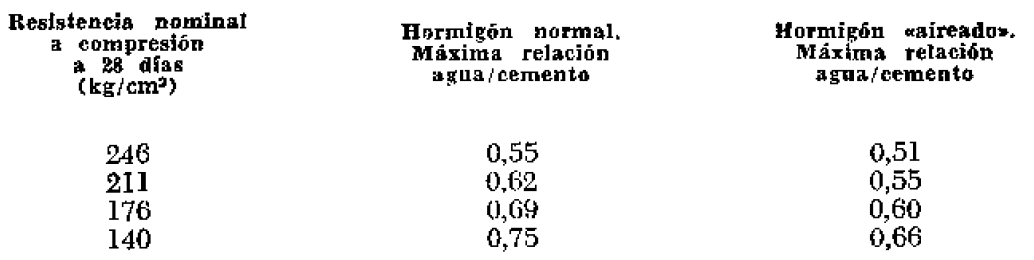

Cuando se utilice homigón «aireado», el aire ocluido no bajará del 3 por 100 ni pasará del 6 por 100.

4. El tamañ̉o máximo nominal de la grava no pasará de 1 \%/2 pulgadas.

(Normaimente, el inspector de la obra determinaba en cada caso el tamaño máximo de la grava, según las condiciones del elemento a hormigonar y pedía a la «planta» el hormigón correspondiente.)

(En el proyecto de estos edificios se habian considerado las siguientes sobrecargas:

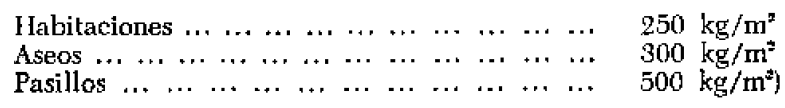

5. Las fórmulas de los hormigones se calcularán para que con los pesos de las mismas se obtenga $1 \mathrm{~m}^{3}$ de hormigón en estado fresco, colocado según se indica en A. S. T. M. C-138-52. 
6. El tiempo dé amasado del hormigón, en el camión hormigonera, no pasará de 1 hora a partir del momento de ia adición del agua.

7. Sin autorización específica, no se colocará hormigón cuando la temperatura del aire sea inferior a $4^{\circ} \mathrm{C}$.

(La temperatura del hormigón no debe pasar de $27^{\circ} \mathrm{C}$, salvo en el caso en que la temperatura del aire sea inferior a $4^{\circ} \mathrm{C}$, en cuyo caso, según A. S. T. M. C-94-48, la temperatura del hormigón no debe pasar de $32^{\circ} \mathrm{C}$.)

\section{Hormigón de pavimento del aeropuerto}

1. El asiento estará comprendido entre 1 y 2 pulgadas.

2. El volumen de aire ocluido en el hormigón estará comprendido entre 3 y 6 por 100 .

3. La resistencia mínima a flexión a 28 días del hormigón determinada en la probeta normal A. S. T. M. y curado en cámara húmeda a $20^{\circ} \mathrm{C}$, será de $45,5 \mathrm{~kg} / \mathrm{cm}^{2}(650$ libras $/$ pulg²).

4. La precisión de los aparatos de dosificación de los constituyentes del hormigón será, como mínimo, del 1 por 100 .

5. El tiempo de mezcla desde que los áridos y el cemento están en la hormigonera no será menor de 1 minuto para masadas de $1 \mathrm{~m}^{3}$ o menores. Todo el agua deberá ser añadida durante $\mathrm{los} 15$ primeros segundos de la mezcla.

6. Sin autorización específica no se colocará hormigón cuando la temperatura del aire, con tendencia a bajar, sea menor de $4^{\circ} \mathrm{C}$ a la sombra, o cuando la temperatura sea menor de $2^{\circ} \mathrm{C}$, con tendencia a subir.

Si se calientan previamente los constituyentes del hormigón, la temperatura de éste, en la descarga estará comprendida entre $20^{\circ} \mathrm{C}$ y $25^{\circ} \mathrm{C}$

Las dosificaciones de los hormigones se calcularán para que con los pesos de las mismas se obtenga $1 \mathbf{~ m}^{3}$ de hormigón en estado fresco, en las condiciones indicadas en A. S. T. M. C-138-52.

\section{Hormigones para el aeropuerto}

1. Al agente plastificante-retardador, utilizado en las condiciones recomendadas por el fabricante, se le exigieron las siguientes condiciones:

a) Producirá un aumento mínimo del tiempo de fraguado del 40 por 100.

b) Aumentará al doble, como mínimo, el asiento del hormigón.

c) La resistencia a compresión a los 3 días, será igual o mayor que la del hormigón sin plastificante.

d) Con el mismc cemento, una relacion agua/cemento más reducida, y el mismo asiento, aumentará la resistencia a los 7 días como mínimo en el 15 por 100.

$\mathrm{E}$ l agua, ensayada según las normas federales SS-R-406 C método núm. 206,0, en mortero de cemento portland, dará cono mínimo el 95 por 100 de la resistencia del mortero equivalente amasado con agua de calidad satisfactoria. 
2. Se utilizará árido de 6 pulgadas de tamaño máximo en el hormigón del muro de coronación del rompeolas y en los bloques prefabricados o moldeados «in situ» de 25 o más toneladas. En los bloques de menos de 25 y y en cimentaciones, se utilizará árido de $2 \frac{1}{2}$ pulgdas.

El árido de 1 1 12 pulgadas de tamaño máximo se utilizará en hormigón en masa, cuando la dimensión mínima del elemento a hormigonar sea de $0,6 \mathrm{~m}$, y en hormigón armado cuya separación mínima entre barras sea mayor de 2 pulgadas. El árido de $3 / 4$ de pulgada se utilizará en toda clase de hormigón, cuando la dimensión mínima del elemento a hormigonar sea menor de $0,6 \mathrm{~m}$, o cuya separación entre barras sea menor de 2 pulgadas.

3. El asiento de los hormigones de árido de tamaño máximo igual o mayor de $2 \mathrm{x} / 2$ pulgadas estará comprendido entre 1 y 3 1/2 pulgadas. (Sin embargo, en la fabricación de los tetrápodos, con árido de $2 \%$ pulgadas, se permitió un asiento máximo de 4 pulgadas.)

Con árido de $1 \% / 2$ pulgadas de tamaño máximo, el asiento estará comprendido entre 2 y 4 pulgadas.

Con árido de $1 / 4$ de pulgada de tamaño mảximo, el asiento estará comprendido entre 2 y 5 puIgadas. (Sin embargo, en el hormigón para la protección de los pilotes del segundo pantalán, se permitió un asiento de 6 pulgadas, a condición de no sobrepasar el límite 0,45 de relación agua/ cemento; en el denominador del quebrado agua/cemento va incluida la puzolana.)

4. A todo el hormigón del puerto, salvo la excepción que se dice a continuación, se le exigió una resistencia mínima a compresión a 28 días de $245 \mathrm{~kg} / \mathrm{cm}^{2}$ y una relación agua/cemento máxima de 0,45. (En el segundo pantalán, a excepción de las losas prefabricadas y del recubrimiento de los pilotes, se permitió utilizar hormigón de resistencia mínima a compresión a 28 días, de 211 kilogramos $/ \mathrm{cm}^{2}$ y relación agua/cemento máxima de 0,55 .)

5. Todo el hormigón llevará puzolana, con una relación puzolana/cemento + puzolana comprendida entre 15 por 100 y 35 por 100 , y un agente plastificante-retardador.

6. Todo el hormigón se dosificará por pesada. La precisión de los aparatos de medida será como mínimo de 1 por 100.

7. El tiempo mínimo de amasado, a partir del momento en que el cemento y los áridos entran en la hormigonera, será de 1 minuto para hormigoneras de $0,76 \mathrm{~m}^{2}$ de capacidad o menores. Se aumentará dicho tiempo en 15 segundos por cada $0,76 \mathrm{~m}^{s}$ o fracción adicional de capacidad. Todo el agua se verterá en el tambor antes de un cuarto del tiempo total de amasado. La velocidad periférica del tambor será, aproximadamente, de $61 \mathrm{~m} /$ minuto.

El tiempo máximo comprendido entre el comienzo del amasado y la colocación del hormigón, no pasará de 1 hora. Después de terminar el amasado, el tiempo máximo hasta la colocación del hormigón será de 30 minutos.

Las dosificaciones del hormigón se determinarán para que con los pesos de las fórmulas, se obtenga $1 \mathrm{~m}^{\mathrm{a}}$ de hormigón en estado fresco, en las condiciones descritas en A. S. T. M. C-138-44.

Siempre que el árido del hormigón sea de tamaño superior a 2 pulgadas, antes de realizar el ensayo de asiento, se cribará el hormigón por el tamiz de 2 pulgadas de luz de malla cuadrada. El hormigón no se verterá con caída libre mayor de 2 metros.

El hormigón se vibrará con unidades de vibración interna de frecuencia no menor de 7.000 pulsaciones por minuto. El intervalo máximo entre masadas en el hormigonado de una sección será de 30 minutos. 
El tiempo de curado mínimo del hormigón será de 21 días en los elementos prefabricados y 14 días para el resto del hormigón. (Todo el curado del hormigón se realizó con líquidos formadores de nembrana.)

No se desencofrará ningún elemento hasta que pueda soportar el peso propio y las cargas de trabajo con un coeficiente de seguridad mínimo de 2.

\section{Hormigón y alambres para las viguetas pretensadas}

I. Todo el hormigón se dosificará por pesada y tendrá una resistencia mínima a 28 días, en probeta cilíndrica, de $350 \mathrm{~kg} / \mathrm{cm}^{2}$.

2. La resistencia mínima del hormigón en el momento de cortar alambres, será de $265 \mathrm{~kg} / \mathrm{cm}^{2}$.

3. Los alambres o cables serán de acero estirado en frio, y tendrán una resistencia a tracción de $160-180 \mathrm{~kg} / \mathrm{mm}^{2}$.

4. El límite elástico aparente (tensión mínima que produce una deformación permanente de 0,2 por 100), será igual o mayor del 80 por 100 de la tensión de rotura del acero.

5. El alargamiento en rotura del alambre no será menor del 2,5 por 100 determinado en una longitud de 10 pulgadas.

\section{Bloques prefabricados}

\section{a) Bloques de carga huecos.}

Los bloques de carga, al ser entregados, cumplirán con las especificaciones A. S. T. M. C-90-52B, en donde se prescribe lo siguiente:

La resistencia mínima a compresión de los bloques será de $49 \mathrm{~kg} / \mathrm{cm}^{2}$, referida al área total horizontal del bloque colocado en la posición que ocupará en obra.

La humedad no pasará del 40 por 100 de la absorción.

Los bloques no presentarán grietas; la superficie será rugosa si ha de ser enfoscada posteriormente. No se permitirán variaciones de más de $3,2 \mathrm{~mm}$ respecto de las dimensiones de los planos.

\section{b) Bloques huecos sencillos.}

En los tabiques de separación de las viviendas se utilizaron bloques huecos sencillos que debían cumplir las especificaciones A. S. T. M. C-129-52, en donde se les exige una resistencia mínima media a compresión de $24,5 \mathrm{~kg} / \mathrm{cm}^{2}$. $140-55$.

La toma de muestras y los ensayos de los bloques se realizarán de acuerdo con A. S. T. M. C- 